Article

\title{
Analysis of the Temperature Changes in the Aburrá Valley Between 1995 and 2015 and Modeling Based on Urban, Meteorological and Energetic Parameters
}

\author{
Enrique Posada ${ }^{1, t, \ddagger}$ and Andrea Cadavid ${ }^{1, \ddagger}$ \\ 1 HATCH INDISA; Carrera $75 \mathrm{~N}^{\mathrm{O}} 48$ A 27 Medellín, Colombia \\ * Correspondence: enrique.posada@hatchindisa.com; Tel.: +57-4-444-6166 Ext:188 \\ + Current address: Affiliation 1 \\ $\ddagger$ These authors contributed equally to this work.
}

\begin{abstract}
There is a perception among the inhabitants of the Aburrá Valley Region, that this heavily populated region, situated in the Andean mountains of Colombia, has been suffering large temperature raises in the last years, especially in the last decade. To give perspective about this issue, the authors have gone through the available information about temperature changes in three meteorological stations in the region and have correlated it with a set of variables of urban, climatic and energetic nature, with the intention of developing an approximate model to understand the temperature changes. Changes in the mean temperature, based on the linear tendencies, were estimated on $0.47^{\circ} \mathrm{C}$ for the 20 years between 1995 and $2015 ; 60 \%$ of change was found to be related to local human activities and $40 \%$ was attributed to the impact of global warming.
\end{abstract}

Keywords: model; temperature; urban; warming

\section{Introduction}

In order to have a better understanding of the environmental behavior of the city of Medellín and its metropolitan area in the Aburrá Valley, situated in the Andean mountains of Colombia, it was proposed to develop two different urban models, which seek to describe the behaviors of the temperature increases in this region in the recent years and how human factors influence this. For the models, the studied time range goes from 1995 to 2015, so historical data is required for the variables to be considered. Data collection was done using different reliable governmental and private sources.

The region to be studied is the Metropolitan Area of the Valley of Aburrá (AMVA by its acronym in Spanish) that is made up by the municipalities of Caldas, Itagüí, Sabaneta, Bello, Copacabana, Girardota, Barbosa, La Estrella, Envigado and Medellín. This is the second largest metropolitan area of Colombia, after the metropolitan area of Bogotá. In total it has approximately 3.7 million inhabitants and urban and rural areas of $102 \mathrm{~km}^{2}$ and $1054 \mathrm{~km}^{2}$ respectively. It is located in the center of the department of Antioquia, on the Andes mountain range with an average elevation of $1538 \mathrm{~m}$. Located on the tropic of cancer, it has quite constant temperatures and small climate variations throughout the year. The area is located in a valley formed by two mountain ranges one to the east and the other to the west and is crossed by the Medellín river, as shown in the following map. 


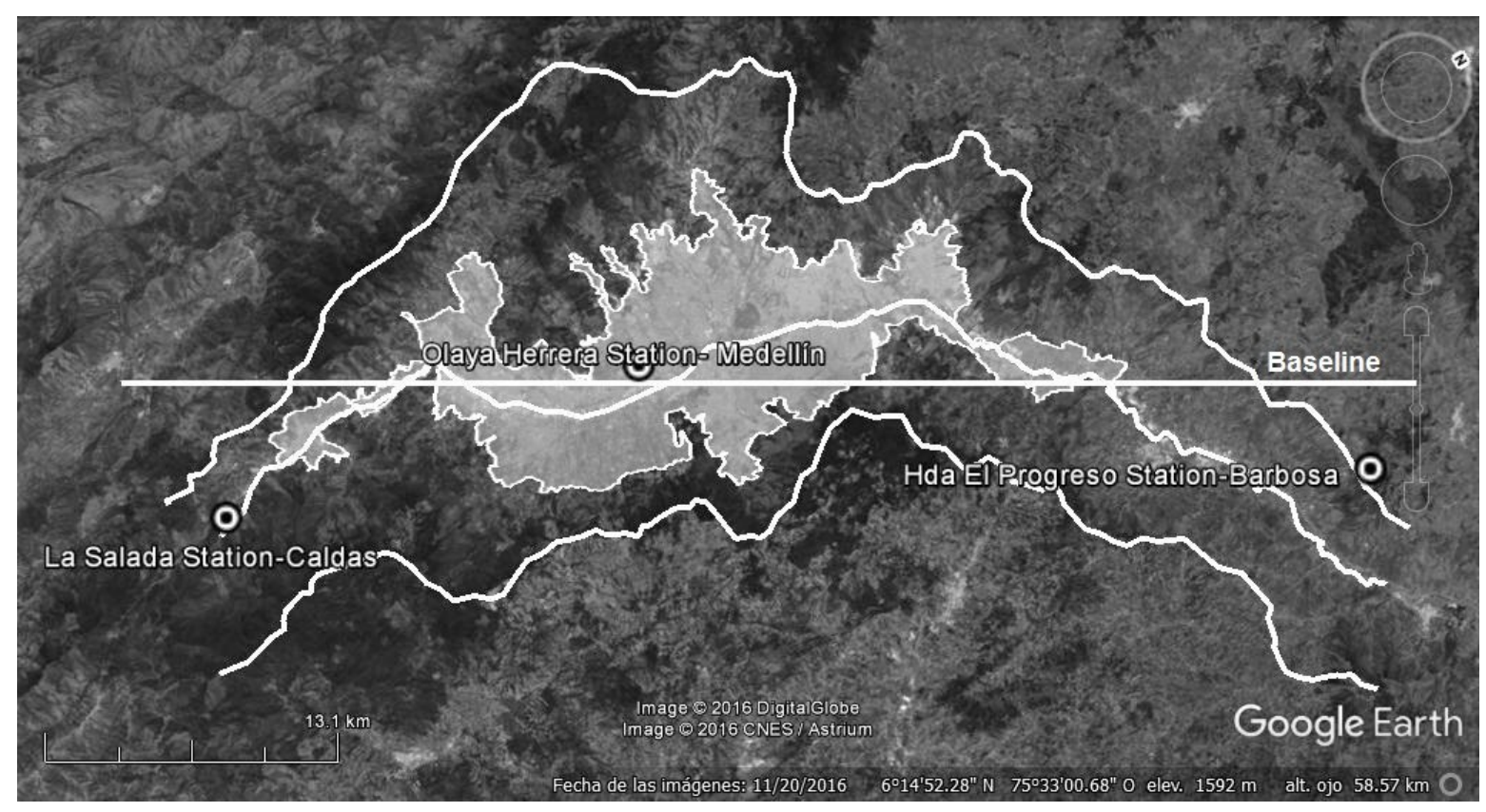

Figure 1. Location of the measuring stations. (c) 2015 Google Inc.

In the Figure 1, there irregular lines are observed, two representing the crests of the mountain ranges on each side of the valley, and a third one, the river that runs through the middle of the valley. A fourth straight line is a reference, called "baseline", which is formed by joining a point in the south with coordinates $602^{\prime} 18.51$ "N $7541^{\prime} 38.70^{\prime \prime} \mathrm{O}$ with a point in the north with coordinates $628^{\prime} 47.19$ " $\mathrm{N}$ $7524^{\prime} 58.90^{\prime \prime} \mathrm{O}$, this line serves as the axis for the location of distances from south to north. The figure also shows a clear demarcated (light in shade) area that is the urban area. The position of the three measuring stations is also displayed. These correspond to meteorological measurement points and are the only stations in the region that have the historical data necessary for the study to be performed. The station Hacienda el Progreso is located in Barbosa, which is an area that is rural in nature and is the place where the winds enter the valley. The station at the Olaya Herrera Airport, located in the center of the valley, corresponds to a clearly urban area and finally the station La Salada in Caldas, is a more rural area and at a higher elevation than the previous two so it is cooler, here the wind leaves the valley. There is the common perception of the citizens that the inhabited zone of the Aburrá Valley is notably increasing its temperature [1] [2]. A survey of 20 people from the engineering company where the authors work, showed that they believe that in the last five years the temperature has increased by $1.97 \pm 1.17^{\circ} \mathrm{C}$ and that the average temperature of Medellín corresponds to $25.11 \pm 2.93^{\circ} \mathrm{C}$. On the other hand, there is endless news about global warming and the way the planet's temperatures are increasing [3]. The authors consider that it is important to study this phenomena with an objective view, to really understand what the heating impact of the urban activities on the zone is as compared to the impact of global warming; and to find which agents could cause the changes. In this way, citizens can better understand the situation and act in some way to assume the changes and mitigate them. This study is a first step in the direction of examining possible solutions.

\subsection{Urban temperature changes. Literature review.}

Several scholars around the world have undertaken the task of understanding, studying, quantifying and seeking alternatives to mitigate temperature changes in urban areas and their areas of influence. There are several types of models that have been developed and presented as tools, and they have a certain similarity with the models presented in this paper. In general, these studies contribute to clarify the variables that are taken into account and their importance in the climate of urban areas around the world. In them it is noticed the global interest and the actuality of this type of studies. 
Several authors seek to characterize urban climate change; Xu et al [4] analyzed five long-term meteorological parameters to characterize climate change in the city of Urumqi, China. Huang and $\mathrm{Lu}$ [5] do something similar for the urban agglomeration of the Yangtze River delta, also in China, where with the use of the maximum, average and minimum temperature observations, a heating rate is determined and compared to the averages, also correlations with factors such as speed of urbanization, population and built area are done. Fujibe [6] analyzes data for 561 stations for 27 years in Japan, where he studies the contribution of urban effects to temperature trends, classifying the stations by the population density around them.

Another field is the Urban Heat Islands, (UHI) studies. For example, Grimmond [7]seeks to estimate the local effect of cities on climate, as well as their causes, dynamics and mitigation strategies, Lauwaet et al [8] estimate the heat island in Brussels and project it to 2060- 2069, by relating meteorological parameters with the UHI. Fuentes [9] does the same for Tampico, Mexico, characterizing the urban zone and studying the historical macro climate to determine the urban heat island. Stone [10] makes an analysis for 50 metropolitan areas in the United States and establishes the warming per decade for urban and rural areas and heat island intensity for 50 years.

In works like Djedjig et al [11], Malys et al [12] and Sharma et al [13], it is sought to quantify the effect of different land surfaces in urban climatology, the first two study the mitigation of the heat island effect through the use of green roofs and walls and the latter determines the heating potential of three different land uses.

Most of the found models are based on energy balances, these study the energy flows of the city or account the energy inputs as well as its consumption characteristics. In the work of Kiss [14] a model of the city of Pécs, Hungary is presented, which takes into account the energy from heating, electricity and transport. The study by Chow et al [15] estimates the heat emissions of anthropogenic nature, with inventories of population density, traffic and electricity consumption for the city of Phoenix, United States. Song et al [16] propose a mass and energy balance model, which evaluates the efficiency of 31 Chinese cities and determine their sustainability; inputs and outputs such as energy, materials, investment capital, waste, production and others are considered. In the city of Kiruna, Sweden, Johansson et al [17] analyzed the energy model to see the possibility of achieving the performance goals imposed by the national government.

At the national level there are models of determination of energy flows for the city of Pasto by Gómez et al [18], they present it as a tool for the planning of a sustainable city. For the city of Bogotá there is the work of Diaz [19],[20],[21] in which he seeks to understand the urban metabolism, with the quantification of inputs and outputs of energy, food, fuels, among others, versus their methodologies of supply, transformation, consumption and disposal to determine their impact and diagnose the sustainability of the metropolis.

No studies were found applicable to the Aburrá Valley. Nor there are studies that use the modeling strategies proposed here.

\section{Materials and Methods}

The starting point is the collection of data from different sources of information for the diverse sets of variables.

\subsection{Information about the climate}

Table 1 shows the mean measured values of temperature in the different stations of the Valley and the precipitation, radiation, wind speed and direction of the predominant wind in the Olaya Herrera Airport station. The variables in this group are the climate ones that are thought to have influence or are associated with the temperatures of the city. 
Table 1. Values of the different climatic variables to be considered in the study.

\begin{tabular}{|c|c|c|c|c|c|c|c|c|c|}
\hline \multicolumn{3}{|c|}{ Information about the climate } & \multicolumn{2}{|c|}{ Units } & 1995 & 1996 & 1997 & 1998 & 1999 \\
\hline \multicolumn{3}{|c|}{ TM. Medellín Temperature (Olaya Herrera) } & \multicolumn{2}{|l|}{${ }^{\circ} \mathrm{C}$} & 22,4 & 22,1 & 23,1 & 23,3 & 21,9 \\
\hline \multicolumn{3}{|c|}{ TC. Caldas Temperature (La Salada) } & \multicolumn{2}{|l|}{${ }^{\circ} \mathrm{C}$} & 18,1 & 16,0 & 18,4 & 18,8 & 17,4 \\
\hline \multicolumn{3}{|c|}{ TB. Barbosa Temperature (Hda El Progreso) } & \multicolumn{2}{|l|}{${ }^{\circ} \mathrm{C}$} & 22,0 & 21,6 & 22,0 & 21,8 & 22,0 \\
\hline \multicolumn{3}{|c|}{ P. Annual Precipitation } & \multicolumn{2}{|c|}{$\mathrm{mm}$} & 1.771 & 1.934 & 1.402 & 1.728 & 2.232 \\
\hline \multicolumn{3}{|c|}{ RI. Radiation index (based on Solar Brightness) } & \multicolumn{2}{|c|}{$\mathrm{h} / \mathrm{h}$ mean } & 0,96 & 0,93 & 1,02 & 0,98 & 0,91 \\
\hline \multirow{2}{*}{\multicolumn{3}{|c|}{ WV. Wind Velocity }} & \multicolumn{2}{|c|}{$\mathrm{m} / \mathrm{s}$} & 0,81 & 0,90 & 1,02 & 1,03 & 0,73 \\
\hline \multicolumn{2}{|c|}{ WD. Predominant wind direction } & & \multicolumn{2}{|c|}{-} & $\mathrm{N}$ & $\mathrm{N}$ & $\mathrm{N}$ & $\mathrm{N}$ & $\mathrm{N}$ \\
\hline Info. about the climate & Units & 2000 & 2001 & 2002 & 2003 & 2004 & 2005 & 2006 & 2007 \\
\hline TM. & ${ }^{\circ} \mathrm{C}$ & 22,2 & 22,9 & 23,3 & 23,0 & 23,0 & 23,1 & 23,0 & 22,7 \\
\hline TC. & ${ }^{\circ} \mathrm{C}$ & 17,4 & 18,1 & 18,3 & 18,2 & 18,0 & 18,5 & 18,6 & 18,6 \\
\hline TB. & ${ }^{\circ} \mathrm{C}$ & 22,3 & 23,0 & 22,8 & 22,9 & 22,8 & 23,0 & 22,9 & 22,3 \\
\hline P. & $\mathrm{mm}$ & 2.132 & 1.412 & 1.450 & 1.650 & 1.844 & 1.801 & 2.025 & 2.048 \\
\hline RI. & $\mathrm{h} / \mathrm{h}$ mean & 1,01 & 1,05 & 1,10 & 1,03 & 1,06 & 1,00 & 0,97 & 1,01 \\
\hline WV. & $\mathrm{m} / \mathrm{s}$ & 0,93 & 0,98 & 0,93 & 0,85 & 0,92 & 0,88 & 0,82 & 0,83 \\
\hline WD. & - & $\mathrm{N}$ & $\mathrm{N}$ & $\mathrm{N}$ & $\mathrm{N}$ & $\mathrm{N}$ & $\mathrm{N}$ & $\mathrm{N}$ & $\mathrm{N}$ \\
\hline Info. about the climate & Units & 2008 & 2009 & 2010 & 2011 & 2012 & 2013 & 2014 & 2015 \\
\hline TM. & ${ }^{\circ} \mathrm{C}$ & 22,1 & 23,0 & 23,0 & 22,4 & 22,9 & 23,2 & 23,2 & 23,9 \\
\hline TC. & ${ }^{\circ} \mathrm{C}$ & 17,5 & 18,2 & 18,1 & 17,2 & 17,6 & 17,9 & 18,1 & 18,6 \\
\hline ТВ. & ${ }^{\circ} \mathrm{C}$ & 21,2 & 22,1 & 22,6 & 21,5 & 21,8 & 22,1 & 22,3 & 22,7 \\
\hline P. & $\mathrm{mm}$ & 2.446 & 1.504 & 2.220 & 2.518 & 1.489 & 1.740 & 1.910 & 776 \\
\hline RI. & $\mathrm{h} / \mathrm{h}$ mean & 0,89 & 1,05 & 0,90 & 0,90 & 1,01 & 1,02 & 1,06 & 1,09 \\
\hline WV. & $\mathrm{m} / \mathrm{s}$ & 0,77 & 1,35 & 0,83 & 0,95 & 0,94 & 0,94 & 0,94 & 0,95 \\
\hline WD. & - & $\mathrm{N}$ & $\mathrm{N}$ & $\mathrm{N}$ & $\mathrm{N}$ & $\mathrm{N}$ & $\mathrm{N}$ & $\mathrm{N}$ & $\mathrm{N}$ \\
\hline
\end{tabular}

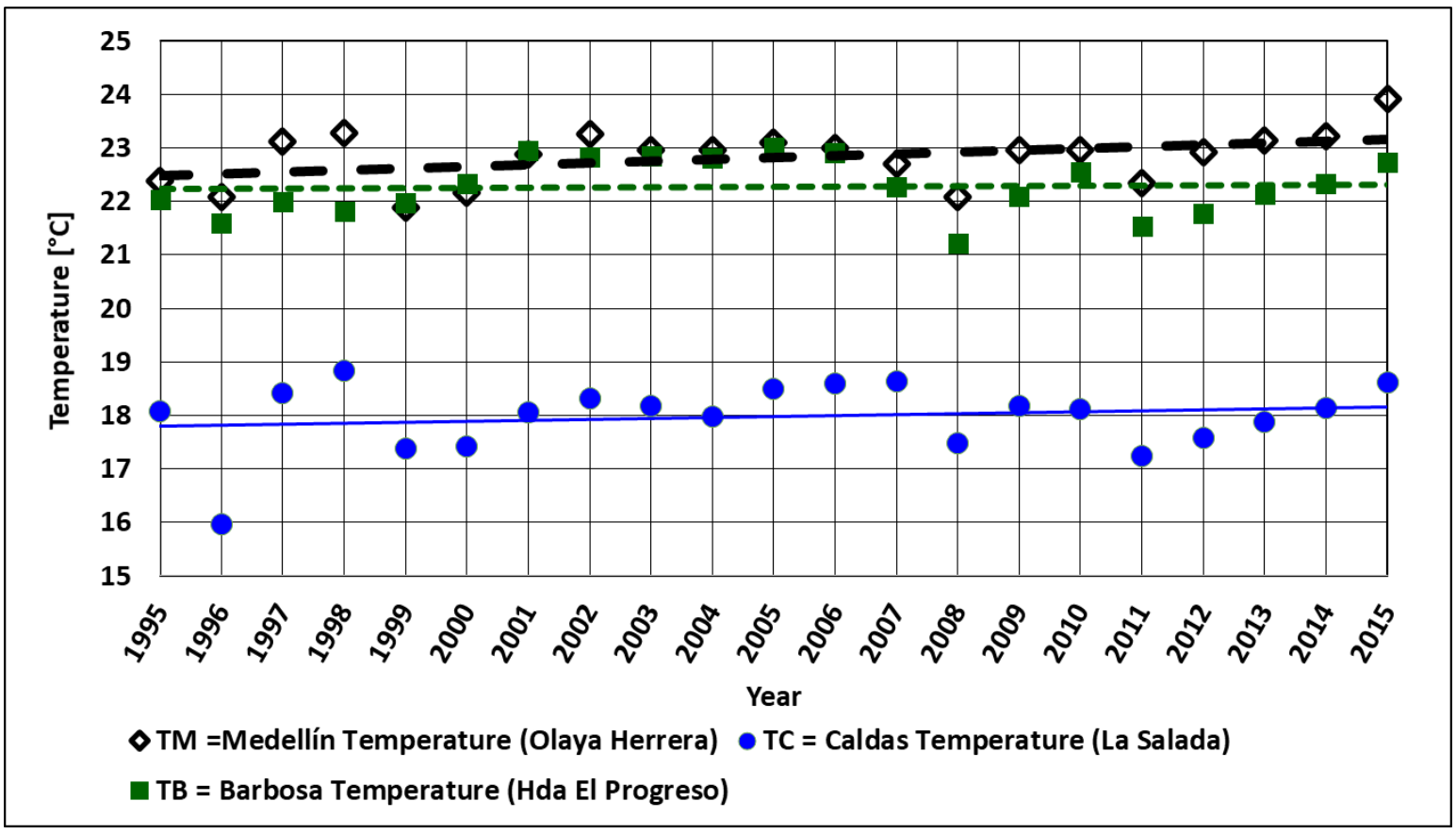

Figure 2. Average annual temperatures for Barbosa (Hda el Progreso), Medellín (Olaya Herrera) and Caldas (La Salada) stations and their respective linear adjustments between 1995 and 2015. 
The main variable to be studied, temperature, is collected from IDEAM, a reliable data source, "a public institution of technical and scientific support to the National Environmental System, which generates knowledge, produces reliable, consistent and timely information, on the state and dynamics of natural resources and the environment" [22]. Historical data was obtained for the three stations mentioned above. The model considers the average annual temperature. It is observed in Figure 2 the evolution in time for the three measuring stations and their linear adjustment that allows observing each trend.

As shown in Figure 2, mean temperatures vary from year to year, with variable behaviors that cannot be easily explained. In any case it is observed that there are trends. In the case of Medellín and Caldas there is a tendency to growth, while in Barbosa the tendency is to remain fairly constant, with a very small increase. These observations allow to assert that the causes for the warming in Medellín and Caldas have to do with the human activities in the urban area of the Valley of Aburrá, since these stations somehow have urban nature and receive the influences of the urban activities, stimulated by the predominant direction of the wind, from north to south, from Barbosa to Caldas. In contrast the Barbosa station does not receive this type of influences. But all of this has to be looked at within the context of geographic variables, especially altitude above sea level of the station, since in the mountainous tropical region temperatures tend to change with elevation.

\subsubsection{Annual precipitation}

The rains were characterized based on the annual precipitation at the Olaya Herrera Airport station; data is obtained from the IDEAM database. This variable is relevant because it must be assumed that it is related to the temperatures, given the energy exchanges associated with the evaporation of rainwater. Figure 3 shows the behavior in the study period, significant annual variations are observed, with a relatively stable average trend during the 20 years, around $1,840 \mathrm{~mm}$, with a very slight increase in time.

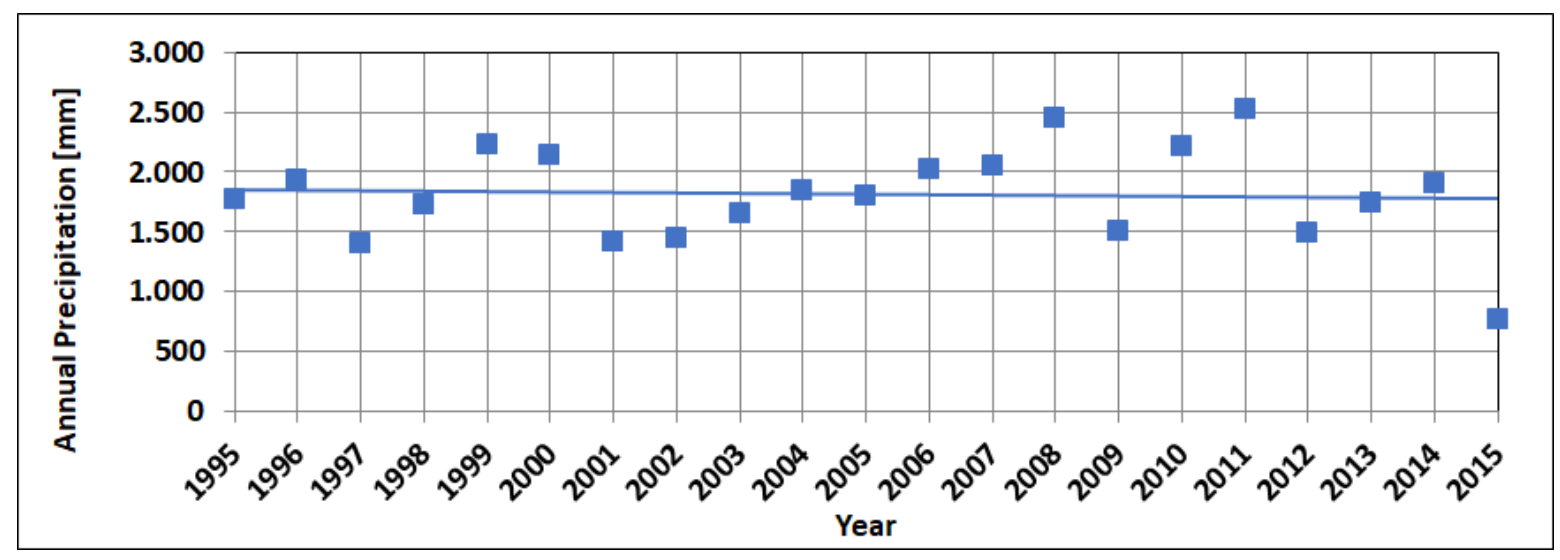

Figure 3. Annual precipitation in the studied years

\subsubsection{Sunshine duration}

This variable is measured by the IDEAM at the Olaya Herrera station, as the daily hours of solar brightness. For the study, the annual daily averages are considered and have been compared with the average of the study time, which for the period of available measurements (since 1998), was 4.94 hours daily. The result of the ratio between the average value of each year and this average of all measurements has been taken as an indicator of solar brightness, which is related to solar incident radiation in the region. In Table 1 the values between 1995 and 1998 were estimated based on a correlation between average temperature and sunshine duration. This variable was taken as indicating solar radiation effects. 


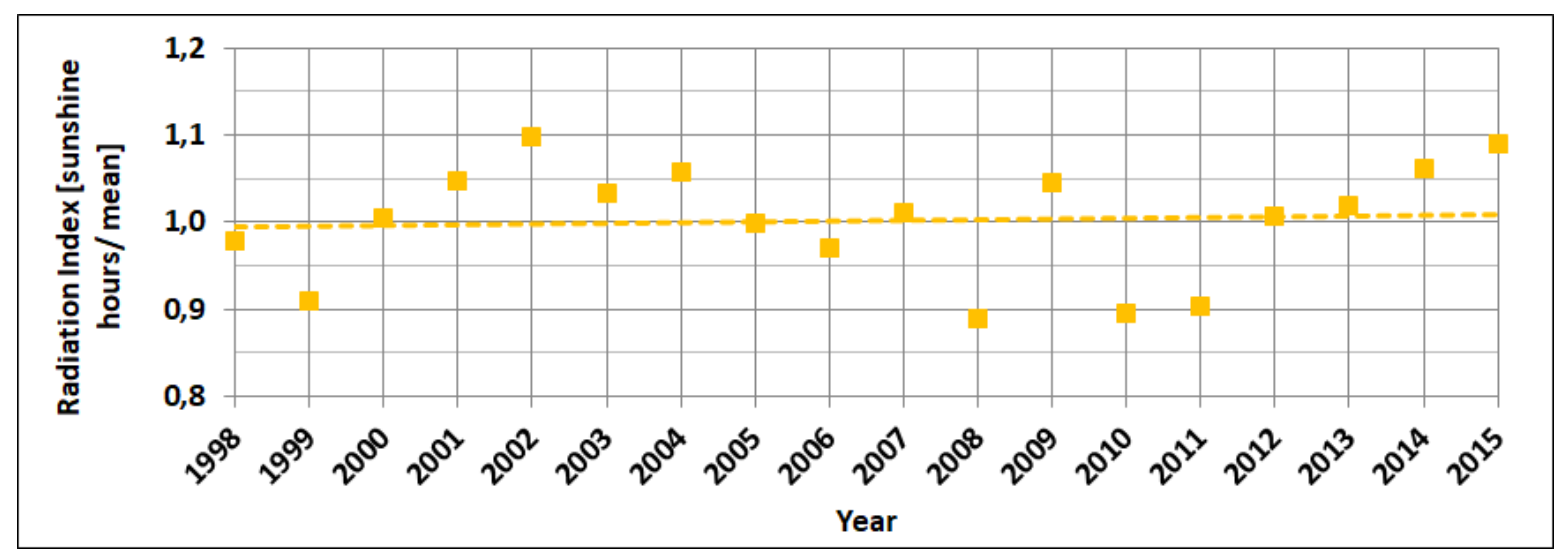

Figure 4. Radiation index in the metropolitan area for the studied years.

\subsubsection{Wind Velocity}

The average wind Velocity data for each of the study years was used and obtained for the Olaya Herrera Airport station from IDEAM. Relatively constant annual mean values were observed in the study period, on which the mean value was $0.92 \mathrm{~m} / \mathrm{s}$. In 2009 there is an unusual peak of $1.35 \mathrm{~m} / \mathrm{s}$.

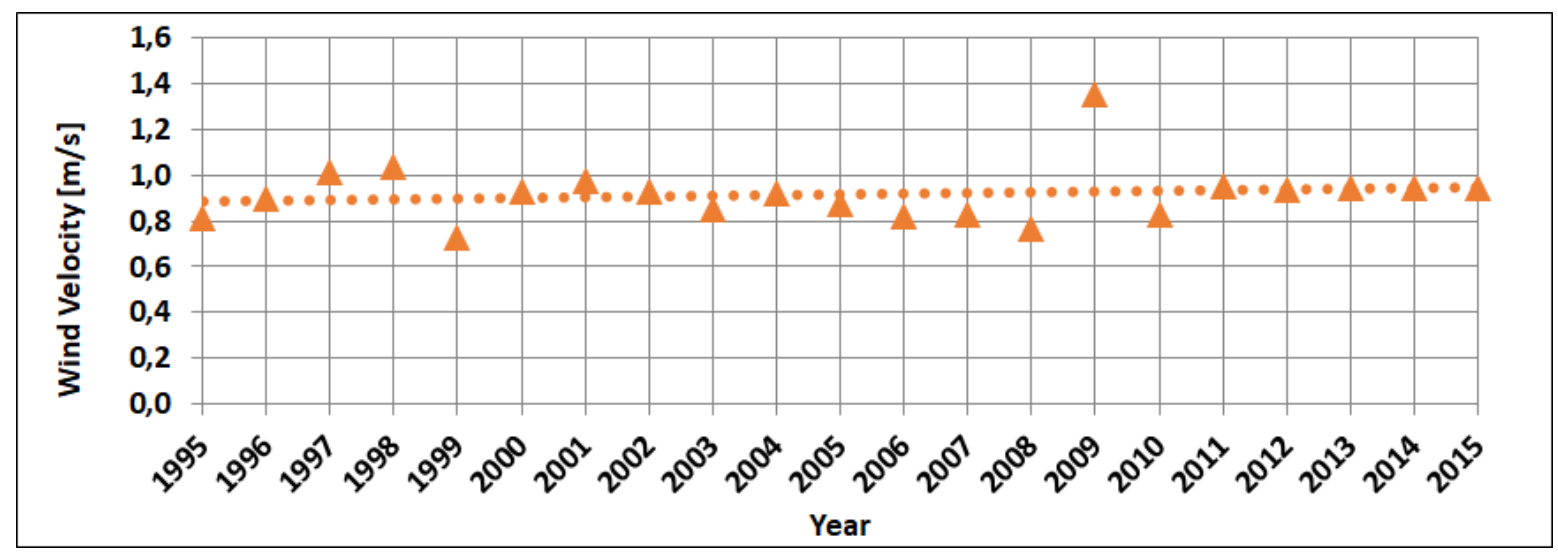

Figure 5. Average annual wind velocities.

\subsection{Geographical information}

Different geographic features have been considered in the study because of their influence on the climate, like elevation above sea level and also their association with urban activities. Likewise, the temperatures and the flow of the river have been taken into account.

\subsubsection{Elevation of the topographic levels of the valley}

The elevation above sea level has an effect on the climate in tropical mountain regions. The following figure shows the geographical situation in the Aburrá Valley, showing the height of the mountain ranges to the east and west of the valley and the height of the river. The graph has taken as a reference the straight line shown in Figure 1, called baseline. The elevations of the points of the three considered topography lines were taken at points joined perpendicularly from each line to the baseline.

It is observed that the river descends 552 meters in the 51 kilometers of the baseline, going from $1,862 \mathrm{~m}$ to $1,301 \mathrm{~m}$, with an average height of $1,505 \mathrm{~m}$ as it passes through the valley. The two mountain ranges have maximum heights of around $3,000 \mathrm{~m}$. The average elevation of the eastern mountain range is $2,584 \mathrm{~m}$ and for the western one is $2,529 \mathrm{~m}$. The average elevation in relation to the river is $1,078 \mathrm{~m}$ and 1,024 for the eastern and western ranges respectively. 




Figure 6. Elevation profile for the Aburrá Valley.

\subsubsection{Width of the Valley}

An analysis of the width of the valley was made at different elevations, 50, 100 and 200 meters above the level of the river, as well as in the ridges of the mountain ranges that form the valley. This was done for different points following the already described reference line that connects two reference points of the valley from south to north. It can be seen in Figure 7 that the valley it is relatively enclosed, with total areas of $108 \mathrm{~km}^{2}$ in the flat zone near the river less than $50 \mathrm{~m}$ above the level of the same, of $166 \mathrm{~km}^{2}$ in the zone of less than $100 \mathrm{~m}$ above the level of the River, of $227 \mathrm{~km}^{2}$ for the zones of less than $200 \mathrm{~m}$ above the level of the river and of $718 \mathrm{~km}^{2}$ between the ridges of the two mountain ranges that form the valley. The fact that the valley is a box-like system allows it to be seen as a volume of control in which mountains act as clear boundaries through which energy and air do not flow significantly. On the other hand, the southern and northern ends are inlets and outflows, especially if is taken into account that the winds have predominant directions from the north, following the direction opposite to the flow of the river.

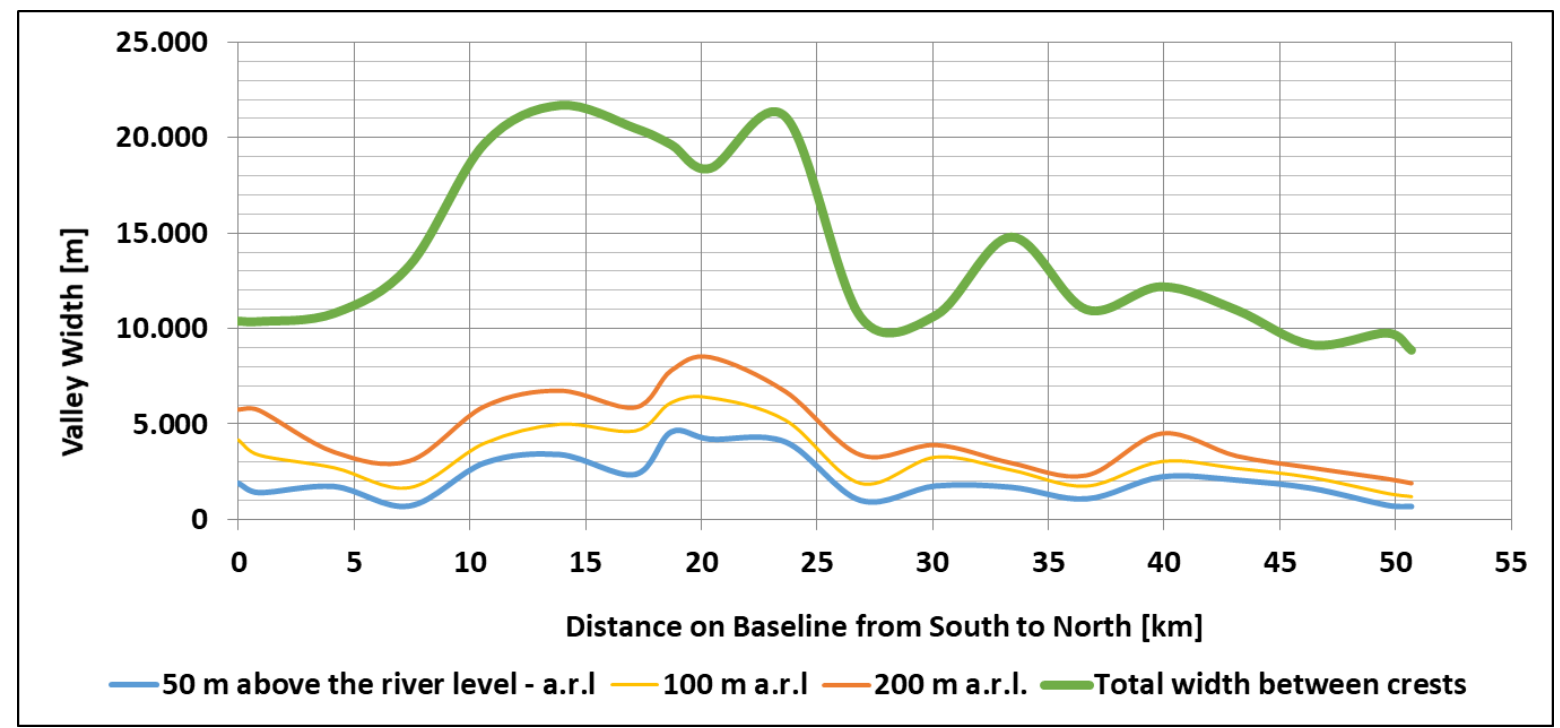

Figure 7. Width of the valley in different points, at different heights. 


\subsubsection{River temperature and flow}

It has been considered that the river acts as a sink that evacuates part of the heat generated by the energy systems of the region. It is estimated that, on average, the Medellín River has an average flow at the entrance to the AMVA of $1.0 \mathrm{~m}^{3} / \mathrm{s}$ and that after passing through the urban area it has $30 \mathrm{~m}^{3} / \mathrm{s}$; this means an average difference of $29 \mathrm{~m}^{3} / \mathrm{s}$. In order to analyze the impact on the model based on differences in water temperatures, a study by Posada et al [23] is used, which analyzes the increases in river temperature in zones with urban impact in the year 2006, corresponding to the stretch between stations E2 and E14, that means, the Primavera Station (south of the valley) and Parque de las Aguas station (north of the valley, area in which the Medellín River receives a high flow of water coming from the diversion of the Rio Grande, which causes the cooling of the waters and a new temperature pattern). The temperature delta thus considered, was on average, $4.5^{\circ} \mathrm{C}$, as shown in Figure 8. Using this information, the magnitude of the heat sink caused by the river in 2006 was estimated, which was 546.4 MW. This magnitude was compared for that year with all the energy coming from the anthropogenic activities and a factor was found that relates the sink to the total of the energetic contributions. This factor was applied to the other considered years since there was no information for river temperatures in the other years of the study.

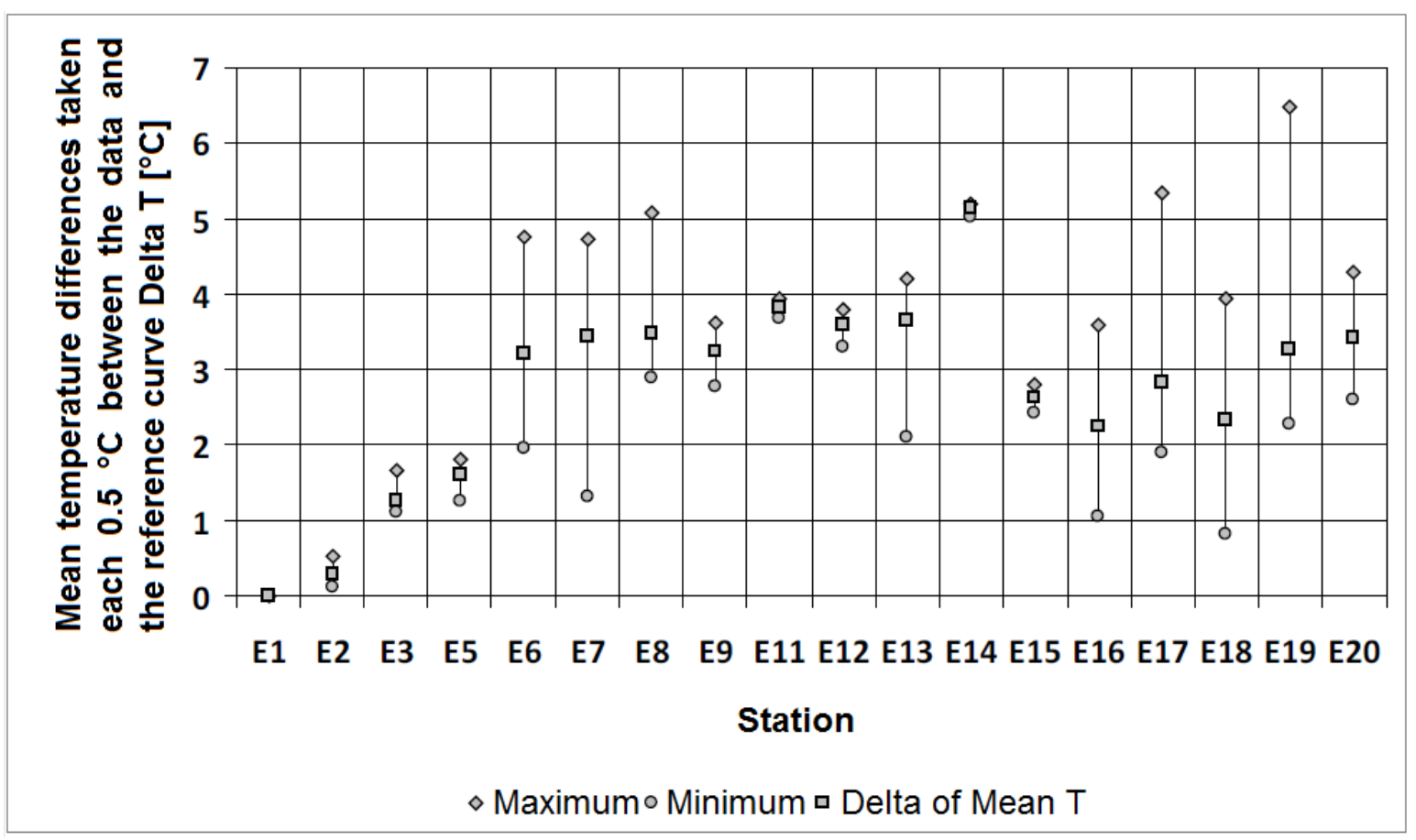

Figure 8. Temperature of the river in each of the measuring stations. Figure taken and edited from the study by Posada et al [23].

\subsection{Information on demographic and economic variables}

For the modeling, the influence of human activity has been considered. For this purpose, demographic variables have been considered, as well as those related to the economic activity of the area. With these variables, a model has been developed, which includes the direct impact of energy variables and the indirect impact of demographic and economic variables. In the analysis, for each variable of this group a change factor was determined. It allows to visualize the variables as a dimensionless set, it is important because the model works with variables of different types and measuring units. That is why indexes have been created; they correspond to the relation between the real values for each given year divided by the value of the first year of the study. These indexes also quantify the relative growth of each variable. Table 2 shows the data every five years as a preview of 
the data, but the model worked with information for each of the years. In several cases, such as living beings, vehicles and energy, values were processed to obtained equivalent men, equivalent vehicles and equivalent gasoline, respectively, to simplify modeling.

Table 2. Values for the demographic and economic variables considered, every five years.

\begin{tabular}{|c|c|c|c|c|c|c|}
\hline Variables & Units & 1995 & 2000 & 2005 & 2010 & 2015 \\
\hline \multicolumn{7}{|l|}{ Living beings } \\
\hline Men & millions & 0,917 & 1,023 & 1,122 & 1,214 & 1,299 \\
\hline Women & millions & 1,096 & 1,223 & 1,341 & 1,451 & 1,553 \\
\hline Children & millions & 0,662 & 0,739 & 0,810 & 0,877 & 0,938 \\
\hline Rodents (rats y mice) & millions & 36,4 & 40,8 & 44,7 & 47,9 & 50,5 \\
\hline Cats & millions & 0,132 & 0,147 & 0,161 & 0,175 & 0,187 \\
\hline Dogs & millions & 0,667 & 0,744 & 0,816 & 0,883 & 0,945 \\
\hline Total equivalent men & millions & 2,432 & 2,713 & 2,975 & 3,217 & 3,440 \\
\hline \multicolumn{7}{|l|}{ Food and residues } \\
\hline Food consumption & million tons/ year & 1,01 & 1,14 & 1,28 & 1,41 & 1,53 \\
\hline Urban Solid Waste generation & million tons/ year & 0,65 & 0,73 & 0,80 & 0,88 & 0,96 \\
\hline \multicolumn{7}{|l|}{ Economy - annual data } \\
\hline Urban constructed area & $\mathrm{km}^{2}$ & 76,4 & 83,3 & 85,4 & 87,3 & 88,6 \\
\hline Gross Domestic Product GDP & Billon (COP, \$) & 18,5 & 21,1 & 26,0 & 33,0 & 42,7 \\
\hline \multicolumn{7}{|l|}{ Vehicle fleet } \\
\hline Automobiles & thousands & 168 & 209 & 290 & 412 & 575 \\
\hline Motorcycles & thousands & 50 & 69 & 203 & 437 & 718 \\
\hline Buses & thousands & 7,1 & 8,7 & 11,4 & 16,1 & 22,8 \\
\hline Trucks & thousands & 12,0 & 17,0 & 18,7 & 26,5 & 34,3 \\
\hline Taxis & thousands & 3,6 & 8,8 & 20,0 & 45,3 & 78,5 \\
\hline Equivalent Vehicles & thousands & 549 & 741 & 1.001 & 1.549 & 2.229 \\
\hline \multicolumn{7}{|c|}{ Fuels and energy - annual consumption } \\
\hline Gasoline & million gallons & 124,4 & 154,8 & 141,0 & 140,7 & 185,9 \\
\hline Diesel & million gallons & 65,9 & 82,0 & 100,5 & 109,6 & 148,0 \\
\hline CNG for Vehicles & million $\mathrm{m}^{3}$ & 0,0 & 1,4 & 27,2 & 50,9 & 65,6 \\
\hline Natural Gas & million $\mathrm{m}^{3}$ & 178 & 193 & 218 & 295 & 372 \\
\hline Coal & million tons & 0,319 & 0,249 & 0,199 & 0,188 & 0,161 \\
\hline Electricity & $\mathrm{TWh}$ & 4,62 & 4,65 & 5,37 & 6,18 & 7,26 \\
\hline Total Energy & $\begin{array}{l}\text { million Equivalent } \\
\text { gasoline gallons }\end{array}$ & 438 & 482 & 518 & 578 & 723 \\
\hline
\end{tabular}

\subsubsection{Equivalent Men (Living Beings)}

The living beings that inhabit the region contribute with their metabolisms to changing the temperature of the environment. It has been considered that not only are people contributing in this instance, but also other living beings in a close relationship with humans such as pets and domestic rodents (rats and mice). The equivalent men concept seeks to consolidate the number of men, women, children, pets and rodents in the AMVA region. The equivalences between humans are calculated according to the heat emission of each, which means comparing their average metabolism with the one of an average adult man. For animals the equivalence was calculated in accordance to the mean body mass of each type of living being and an activity factor selected by the authors, to compare with respect to an adult male weighing $69.1 \mathrm{~kg}$ [24]. 
Table 3. Metabolic factor and contribution by type of living being.

\begin{tabular}{llll}
\hline Type of living being & Average weight, kg & Metabolic factor & Heat emission, W \\
\hline Grown Man & 69,1 & 1,000 & 104,4 \\
Grown Woman & 60,0 & 0,781 & 81,6 \\
Kid & 40,0 & 0,521 & 54,4 \\
Average Dog & 15,8 & 0,229 & 23,9 \\
Average Cat & 4,1 & 0,047 & 4,9 \\
Average Rodent (rats, mice) & 0,29 & 0,0063 & 0,65 \\
\hline
\end{tabular}

\subsubsection{Food}

This indicator estimates the amount of food consumed by the AMVA inhabitants per year, but it is limited only to humans, the feeding of pets and other living things is not considered. For calculating this indicator the change over time in food intake per person and the quantity of people is taken into account.

\subsubsection{Urban Solid Waste}

It is considered that the amount of waste generated by the population has influence on the heating of the city, since it is an indicator of the consumption habits of a society and its sustainability. The data is taken from a projection made by the AMVA for the formulation of the integrated regional solid waste management plan. [25]

\subsubsection{Constructed Urban Area}

The built area of the city is estimated; here a known value reported in a given year is taken into account. Starting from this value and an annual indicator of the new constructed area, the total constructed area is estimated. This indicator is important since the built areas have a negative impact on the temperature change (causing it to raise) unlike the green areas and parks; these green areas absorb CO2 and heat, so that as the urban area increases, this ecosystem regulation service is somehow lost.

\subsubsection{Gross Domestic Product - GDP}

This is an indicator of the total goods and services produced by AMVA annually; it is a representative value of the productive and services activity of the city.

\subsubsection{Equivalent vehicles}

To calculate this indicator, equivalence factors are found between a light vehicle (automobile) and the other considered vehicles. These equivalences have been estimated based on specific average consumption and daily activity time, for each type compared to a normal automobile. Table 4 shows the used equivalence factors.

Table 4. Equivalence factors between vehicles.

\begin{tabular}{llll}
\hline Type of Vehicle & $\begin{array}{l}\text { Consumption, } \\
\mathbf{k m} / \text { gal urban }\end{array}$ & $\begin{array}{l}\text { Functioning hours } \\
\text { in the day }\end{array}$ & Equivalence factor \\
\hline Automobiles & 30 & 2 & 1.00 \\
Motorcycles & 100 & 2 & 0.30 \\
Buses & 8 & 10 & 18.75 \\
Trucks & 5 & 6 & 18.00 \\
Taxis & 30 & 10 & 5.00 \\
\hline
\end{tabular}


2.3.7. Fuel consumption in terms of equivalent million gallons of gasoline

This is an indicator of the city's energy consumption, since fossil fuels and electricity are counted here. The equivalence is done in relation to the calorific power of each energy source. This indicator can quantify better the influence of transport and energy consumption, because even though the number of vehicles increases, technologies evolve and have better fuel yields (mileages), each time requiring less energy per unit distance.

Table 5. Calorific power of the sources and equivalence factor with gasoline gallons.

\begin{tabular}{llll}
\hline Energy source & Units & $\begin{array}{l}\text { Calorific } \\
\text { power, } \\
\text { MW/unit }\end{array}$ & $\begin{array}{l}\text { Equivalence in } \\
\text { million gasoline } \\
\text { gallons }\end{array}$ \\
\hline Gasoline & Million gallons & 33.822 & 1,00 \\
Diesel & Million gallons & 40.445 & 1,20 \\
CNG for Vehicles & Million $\mathrm{m}^{3}$ & 9.326 & 0,28 \\
Natural Gas & Million $\mathrm{m}^{3}$ & 9.326 & 0,28 \\
Coal & Million tons & 6.782 .532 & 200,5 \\
Electricity & TWh & 1.000 .000 & 29,6 \\
\hline
\end{tabular}

Based on the variables that have been described, a model based on the yearly behavior of the variables has been developed, which includes the direct impact of energy variables and the indirect impact of demographic and economic variables.

\subsection{Information on energetic variables}

A second model has been developed from a purely energetic point of view, based on energy inputs and outputs. For this purpose the average energy fluxes shown in the following table have been considered.

Table 6. Energy contributions from different sources. Data every five years in MW.

\begin{tabular}{llllll}
\hline Energetic input variables [MW] & $\mathbf{1 9 9 5}$ & $\mathbf{2 0 0 0}$ & $\mathbf{2 0 0 5}$ & $\mathbf{2 0 1 0}$ & $\mathbf{2 0 1 5}$ \\
\hline Gasoline & 480 & 598 & 544 & 543 & 718 \\
Diesel & 304 & 379 & 464 & 506 & 683 \\
CNG for Vehicles & 0 & 1,5 & 29 & 54 & 70 \\
Natural gas & 189 & 206 & 233 & 314 & 396 \\
Coal & 189 & 148 & 118 & 111 & 95 \\
Electricity & 527 & 530 & 613 & 705 & 829 \\
Equivalent Gasoline Contribution & $\mathbf{1 . 6 9 0}$ & $\mathbf{1 . 8 6 2}$ & $\mathbf{2 . 0 0 1}$ & $\mathbf{2 . 2 3 4}$ & $\mathbf{2 . 7 9 0}$ \\
Metabolism of equivalent men & $\mathbf{2 6 2}$ & $\mathbf{2 9 2}$ & 320 & 346 & 370 \\
Total Contribution of Sources & $\mathbf{1 . 9 5 2}$ & $\mathbf{2 . 1 5 4}$ & $\mathbf{2 . 3 2 1}$ & $\mathbf{2 . 5 8 0}$ & $\mathbf{3 . 1 6 0}$ \\
\hline
\end{tabular}

According to the previous table, the region receives a total energy contribution that currently exceeds $3000 \mathrm{MW}$. This contribution essentially dissipates into the medium, even if it is useful energy, since eventually it will generate heat, friction, noise and other dissipative forms.

\subsection{Dimensional adjustment and treatment of variables}

\subsubsection{Transformation of temperatures}

As shown in Figure 2, temperatures at the different points in the metropolitan area have different behavior. For the case of Barbosa (Hda. El Progreso), the temperature shows relatively moderate variations in the 20 years of the study. In the case of Medellín (Olaya Herrera) and Caldas (La Salada) a variable but gradual warming is observed, being more prominent in Medellín. This warming is what 
is sought to be attributed to regional anthropogenic reasons in this model. However, it is clear that there are other causes that must be taken into account.

On the one hand are the impacts of phenomena of a global nature, which in principle are distributed on the planet, with certain geographic variations. Figure 9 shows the data provided by the NOAA's National Climatic Data Center [26], with global temperatures of the surface of the earth, compared against the average between 1901 to 2000 (dotted line passing through zero). The impacts of the Niño (increases) and the Niña (decreases) phenomena are observed. In the period from 1995 to 2015, on average, an increase is not observed, but rather decreases. Figure 10 shows the behavior of such global temperatures compared to those of the studied region in the Aburrá Valley. For this purpose, the data has been processed in the following way:

- The data of the global delta temperature was converted to degrees Celsius; the information was digitized to semi-annual and annual values, from which the data of 1995 were subtracted. Thus, DTGS 95 annual and DTGS 95 semi-annual curves were obtained.

- The three annual temperatures of the region, Barbosa (TB, Hda. Progreso), Medellín (TM, Olaya Herrera) and Caldas (TC, La Salada) were taken and their average values in 1995 were subtracted of each, thus obtaining the TM-TM95, TC-TC95 and TB-TB95 curves.

- Third bullet

\section{El Niño/La Niña index since 1980}



Figure 9. Global annual temperatures of the earth surface $\left({ }^{\circ} \mathrm{F}\right)$, compared against the average 1901 to 2000 (dotted line passing through zero), data from NOAA's National Climatic Data Center. The impacts of the Niño (increases) and the Niña (decreases) phenomena are observed [26].

In Figure 10 it is evident that the impacts of the Niño and Niña phenomena are the cause of the temperature oscillations for the three stations in the region. Such oscillations fit quite well to those of global temperatures. However, trends, as seen in linear adjustments, differ from global phenomena to local phenomena. This is to be expected for the behavior of air masses in a relatively long, narrow and enclosed valley between two mountain ranges with $1000 \mathrm{~m}$ height, valley in which the urban activity of nearly four million people has a significant impact. 


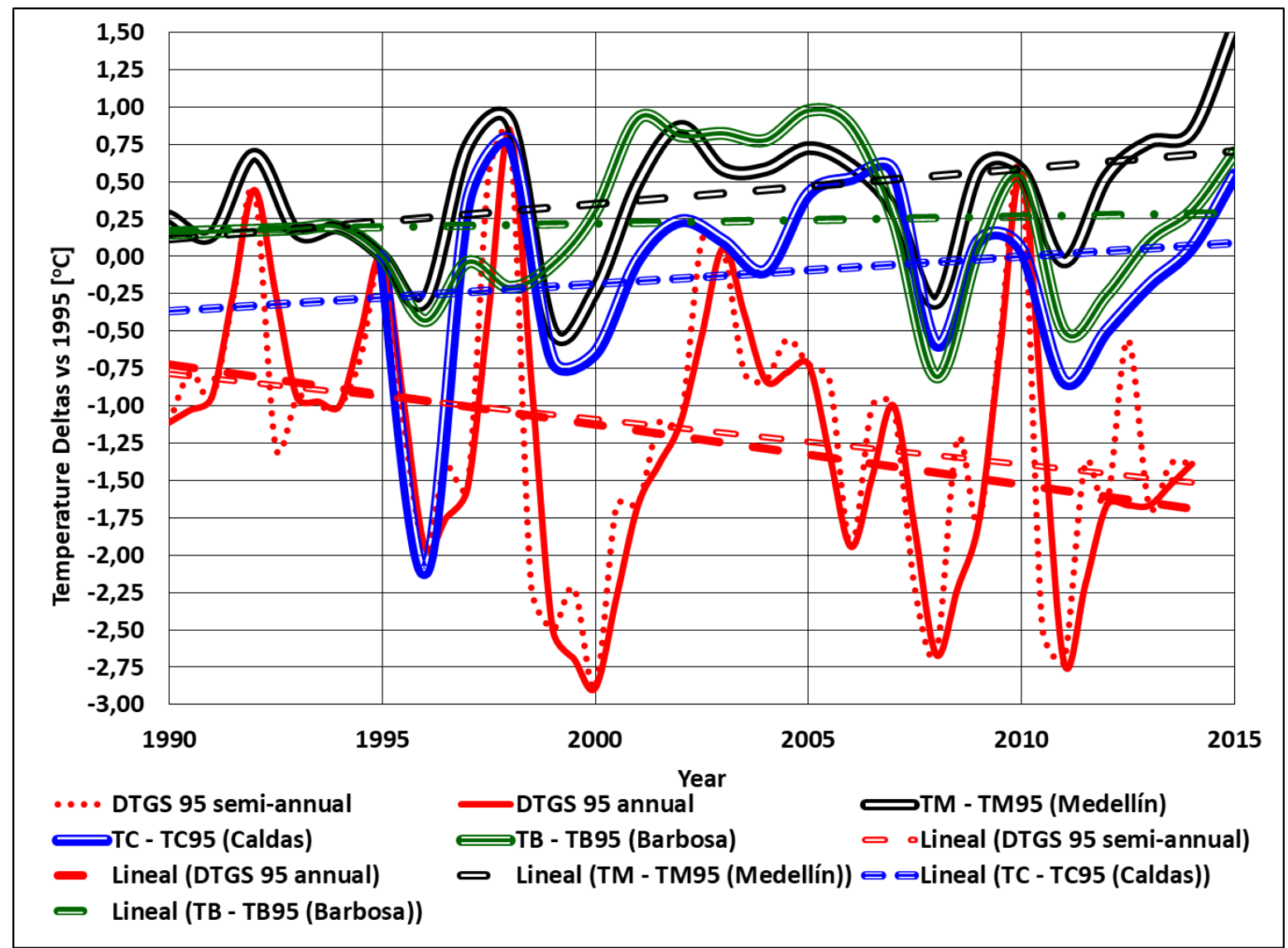

Figure 10. Comparison between the annual global temperatures of the surface of the earth and the temperatures of the stations of the Aburrá Valley (Deltas against 1995).

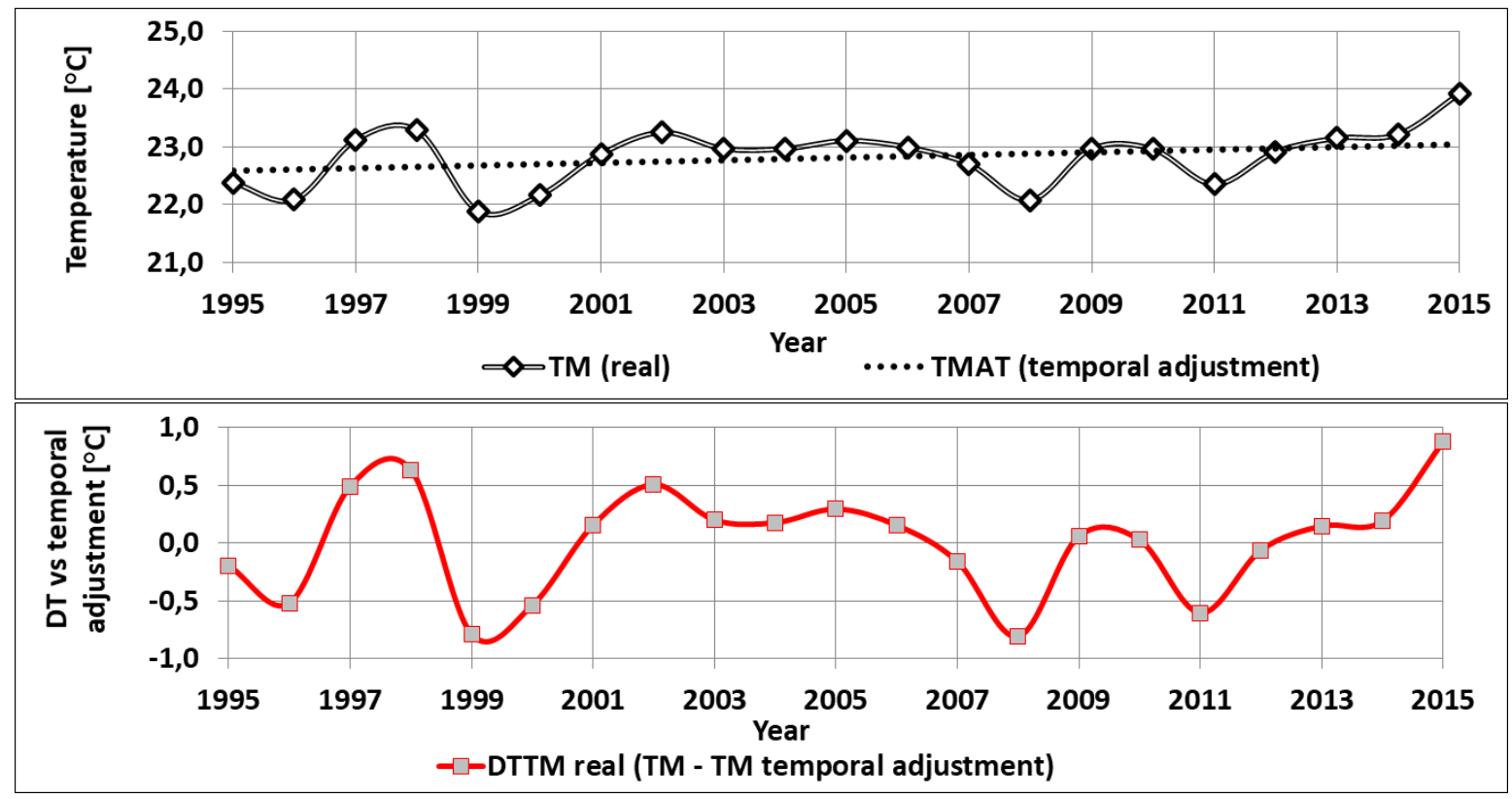

Figure 11. Annual mean temperatures of the Olaya Herrera station, Medellín (TM), TMAT temporal adjustment, and TM deltas against such adjustment (DTTM), for the period 1995 to 2015. 
In order to understand the different aspects affecting temperature, which are of non-anthropogenic nature, it was decided to adjust the temperature behavior of the Medellín station (M) as a function of time in the period 1990 to 2015 and to calculate the temperature deltas obtained by subtracting from the recorded temperature, the temporary adjustment. Figure 11 shows graphically these temperatures and these deltas (defined as DTTM = TM -TM time adjusted).

It was postulated that such deltas (DTTM) depend on phenomena that are not anthropogenic, namely the average annual rainfall, average annual radiations and the universal phenomena of the Niño and Niña, as noted in Figure 9 and Figure 10.

- Global Niño and Niña factor, DTGS (global DTGS vs. global average DTGS), taken from Figure 9 and Figure 10.

- Radiation excess factor (radiation index - minimum radiation index), The radiation index has been defined as the annual sunshine hours divided by the average annual sunshine hours in the studied period. This average value was 1,800 hours per year. The factor is calculated by subtracting from the annual index the minimum registered index (0.86), which occurred in the year 2008 with a total of 1,599 hours.

- Precipitation defect factor (maximum precipitation index - precipitation index). The precipitation index has been defined as the annual precipitation value in $\mathrm{mm}$ of water, divided by the average annual precipitation in the period studied. This average value was $1,811 \mathrm{~mm}$ per year. The factor is calculated subtracting the maximum recorded index (1.39), which occurred for the year 2011 with a total of $2,518 \mathrm{~mm}$, from each of the annual indices.

Figure 12 show the behaviors and the correlations between the DTTM and the said indicators of radiation, precipitation and global phenomenon.

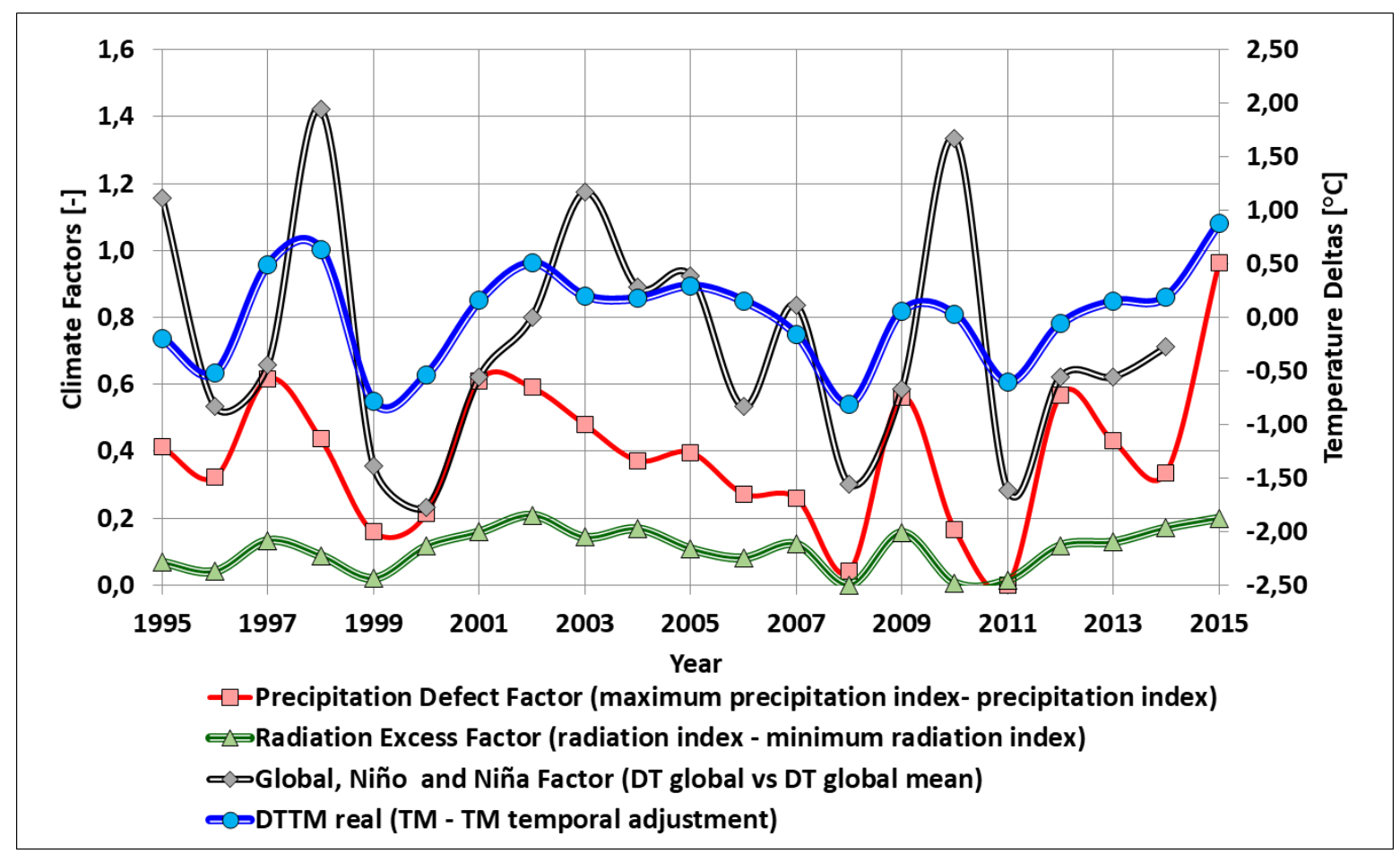

Figure 12. Temperatures deltas for Medellín and global and climate factors between 1995 and 2015.

Table 7 shows the obtained correlations and that can be considered as significant. They are therefore used to predict annual temperature behaviors with relation to DTTM variations against the annual linear adjustment. 
Table 7. Correlations found between the temperature delta and the global temperature change, radiation and precipitation.

\begin{tabular}{ll}
\hline Influence and factors & $\mathbf{R}^{2}$ \\
\hline FIDT global = global, Niño and Niña Factor (DT global vs mean) & 0,400 \\
FIR = Radiation Factor & 0,520 \\
FIP = Precipitation Factor & 0,626 \\
\hline
\end{tabular}

In order to better understand the changes in time already presented in Figure 2, temperatures for stations M and B between 1990 and 2015 are shown in Figure 13 This shows more clearly that the changes in Medellín are greater than the time changes in Barbosa. The first important consideration was to assume that the change in temperatures in Barbosa corresponds to impacts attributable to the mixture of global and local climatic impacts and not to impacts of the activity of the region, this taking into account the situation of such a station in the rural north of the valley, and the predominant direction of the winds, which go from north to south.

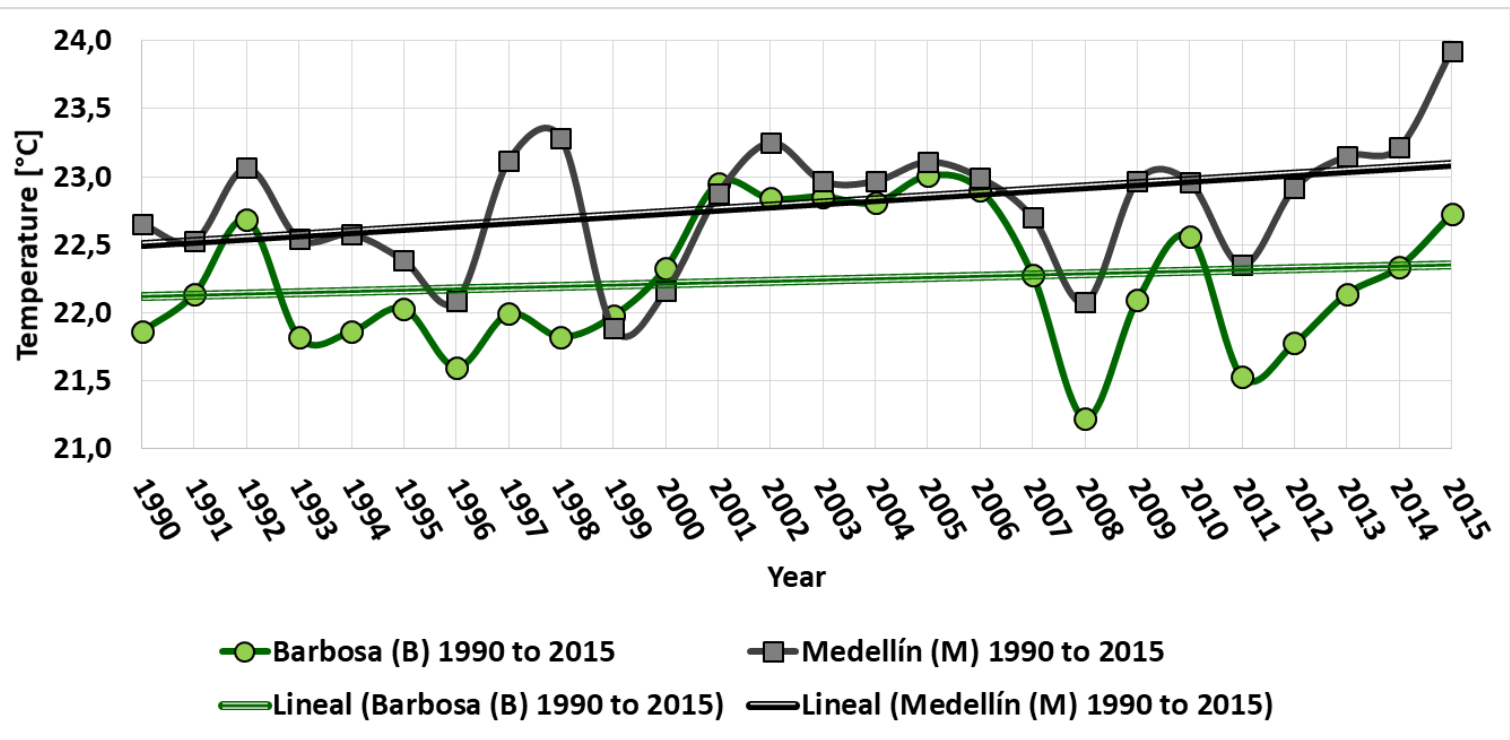

Figure 13. Average annual temperatures in the stations of Barbosa and Medellín between 1990 and 2015 and their linear adjustments over time.

The second consideration is then to assume that the difference between the temporary temperature adjustments of Medellín (TM) and Barbosa (TB) is due to human activity in the region. This activity generates: Bulleted lists look like this:

- Continuous and increasing heat emissions, which origin increases in the temperature of the air passing through the urban area.

- Changes in patterns of heat exchange and absorption and emission of solar radiation. For example, increases in the constructed area and in the corresponding circulation surfaces, ceilings and walls result in changes in surface emissivities and changes in absorptions and reflectivities.

- The presence of atmospheric agents and pollutants resulting from the activity give rise to secondary reactions involving deliveries and consumptions of reaction energies and change in the parameters of absorption and emission of radiation.

A value of $0.06^{\circ} \mathrm{C}$ (DTSNM) has been deducted from the linear adjustment of temperatures in Medellín (TMAT) and Barbosa (TBAT), considering that station $\mathrm{M}$ is at 1,490 $\mathrm{m}$ above sea level and the station B is at a slightly higher elevation, 1,500 meters above sea level. In this way, based on time, the temperature difference due to the activity has been constructed. 


$$
\text { DTAM }=\text { TMAT }- \text { TBAT }- \text { DTSNM }
$$

This DTAM difference is sought to be modeled with the two methods explained below in numeral 2.6

\subsubsection{Indexing of Activity Indicator Variables}

As already mentioned, indices have been created for the different variables, which correspond to the relation between the real value for each year divided by the value for the first year of the study (1995). These indices also quantify the relative growth of each variable.

\subsection{Correlations Establishment}

Two models of linear nature are made to approximate the modeling of temperature increases as a function of the considered anthropogenic activity factors. The first one based on the factors of human activity and the second one based on inputs and outputs of energy to the mixture zone of the atmosphere of the Aburrá Valley.

The first model assumes that the DTAM temperature changes are the result of a linear combination of the indexes of the activity indicator variables.

$$
\operatorname{DTAM}(\text { modeled })=\sum \mathbf{F A i} * \mathbf{I A i}
$$

Where $F A i$ is the activity influence factor $i$ and $I A i$ is the annual activity index $i$.

To find the influence factors for each variable an Excel Solver routine was used. It is important to understand that this is not a closed problem and that there are multiple combinations that approach the real value of DTAM. Therefore, this routine was executed 10 times minimizing in each occasion the average of the absolute values of the annual error (this error was obtained comparing real DTAM against modeled DTAM), changing the initial values of the assumed factors in the interaction, so that different results are obtained each time. At the end the obtained factors are averaged.

Table 8. Dimensions of control volume associated with energy balances.

\begin{tabular}{llll}
\hline $\begin{array}{l}\text { Average elevation of the Mountain ranges from North } \\
\text { to Olaya Herrera in relation to the river elevation }\end{array}$ & $\mathrm{m}$ & 1.086 \\
$\begin{array}{l}\text { Average width from North to Olaya Herrera at } 50 \mathrm{~m} \\
\text { height above the River, flat area }\end{array}$ & $\mathrm{m}$ & 1.923 \\
$\begin{array}{l}\text { Average width from North to Olaya Herrera at } 100 \mathrm{~m} \\
\text { height above the River }\end{array}$ & $\mathrm{m}$ & 2.870 \\
$\begin{array}{l}\text { Average width from North to Olaya Herrera at } 200 \mathrm{~m} \\
\text { height above the River }\end{array}$ & $\mathrm{m}$ & 3.846 \\
$\begin{array}{l}\text { Average width from North to Olaya Herrera at mixing } \\
\text { height (337 m) }\end{array}$ & $\mathrm{m}$ & 5.182 \\
$\begin{array}{l}\text { Average width from North to Olaya Herrera between } \\
\text { crests }\end{array}$ & $\mathrm{m}$ & 12.505 \\
$\begin{array}{l}\text { Control area height for mass balance (mixing height) } \\
\text { Average width to calculate control area }\end{array}$ & $\mathrm{m}$ & 337 \\
\begin{tabular}{l} 
Size of control area \\
\hline
\end{tabular} & $\mathrm{m}$ & 3.552 \\
\hline
\end{tabular}

The second model is based on an energy balance in which the energy inputs described in Table 6 are considered. The heating that the Medellín River suffers due to the activity while passing through the region has been considered in the model as an energy output. A control area has been considered, the width of this area corresponds to an average between the average width of the valley at $50 \mathrm{~m}$ above the river level from Barbosa to Medellín stations and the width between the mountain ranges at the mixing height; the height correspond to the mixing The value of the mixing height has been estimated to achieve a good fit of the model. 
The energy balance is described by the following expression:

$$
\mathbf{Q}_{\text {in }}-\mathbf{Q}_{\text {out }}=\dot{\mathbf{m}} * \mathbf{C}_{\mathbf{p}} * \Delta \mathbf{T}
$$

Where:

$Q_{\text {in }}$ : Annual energy Input to the Control Volume. Comes from the energy sources.

$Q_{\text {out }}$ : Thermal energy output that leaves the control volume through the river.

$\dot{m}$ : Air Mass flow that goes through the control volume.

$C_{p}$ : Specific heat of Air.

$\Delta T$ : Temperature delta between the ends of the control volume.

For the annual energy imput, a percentage of the total energy of the entire Aburrá Valley was considered. This percentage is proportional to the distance in the central axis from the north to the Olaya Herrera station, compared to the total distance between the two ends Caldas and Barbosa, obtaining a percentage of $60.17 \%$; this considers the preferential direction of the wind, from north to south. As for the output of energy carried by the river, a $39.43 \%$ of the same $(100-60.17) \%$ is considered since the River drags energy in the opposite direction to the wind, from south to north.

In order to estimate the annual average mass flow, the average wind speed in the mixing zone which was estimated at 2.64 times the velocity at the surface, was multiplied, by the control area and by the air density, for each considered year.

As already noted, a correlation between climatic and global influences (Figure 12) was established to estimate the variations of DTTM against the annual linear adjustment of TM. This correlation was established by assigning factors of influence to the factors of excess radiation, precipitation defect and global impact of temperature by effects of the Niño and Niña. Such factors were taken as proportional to the $\mathrm{R}^{2}$ correlation factors of Table 7 and were chosen using the Excel Solver routine to minimize the differences between real DTTM and modeled DTTM according to the expression:

$$
\text { DTTM }_{\text {modeled }}=\mathbf{F I P} * \text { IP }+ \text { FIR } * \text { IR }+ \text { FIDTglobal } * \text { GlobalNiño\&Niñafactor }
$$

\section{Results and Discussion}

\subsection{Model of global and climate impacts on variations}

The following results were obtained with the model.

Table 9. Factors of influence found for global temperature change, radiation and precipitation.

\begin{tabular}{lll}
\hline Influence and factors & $\mathbf{R}^{2}$ & Factors \\
\hline FIDT global = Global Niño and Niña & 0,400 & 0,267 \\
factor (DT global vs mean) & 0,520 & 0,347 \\
FIR = Radiation factor & 0,626 & 0,418 \\
FIP = Precipitation factor & & \\
\hline
\end{tabular}

Figure 14 shows the obtained model, which is quite accurate and it indicates that indeed the TM variations versus its temporal adjustment are essentially due to global and climatic phenomena. 


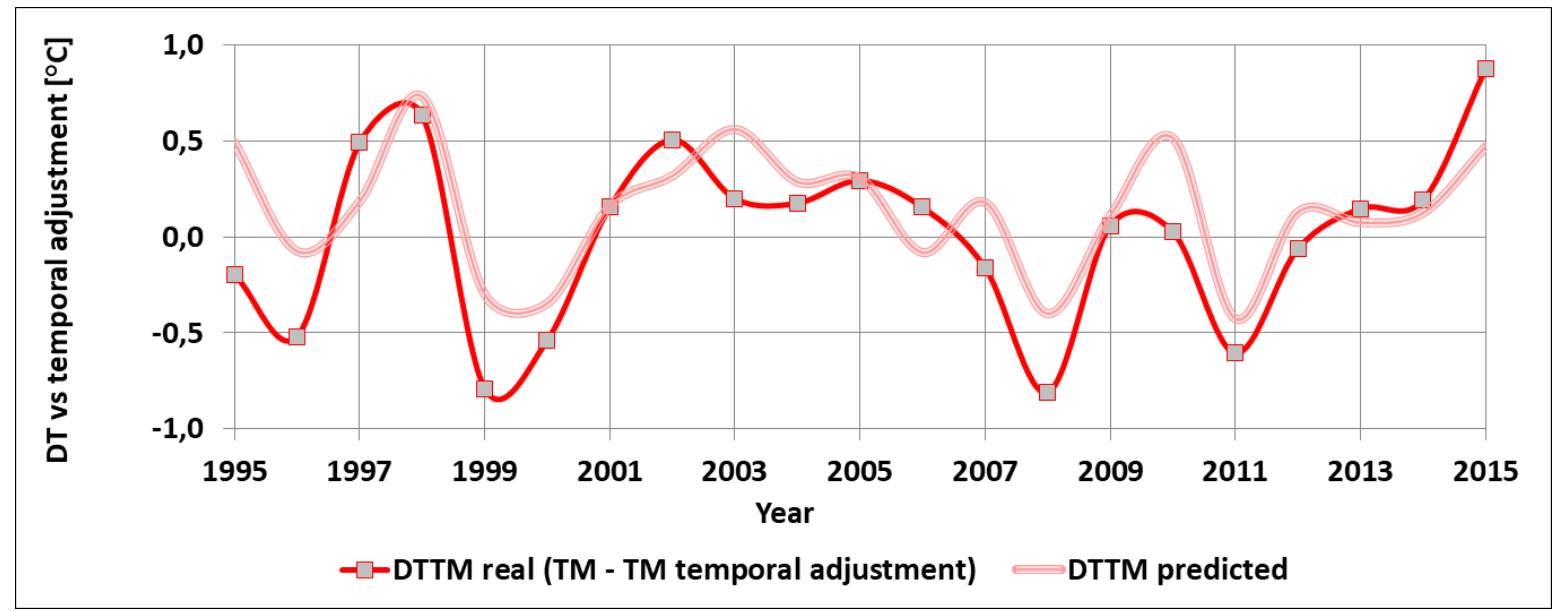

Figure 14. Modeling TM variations versus their temporal adjustment (DTTM).

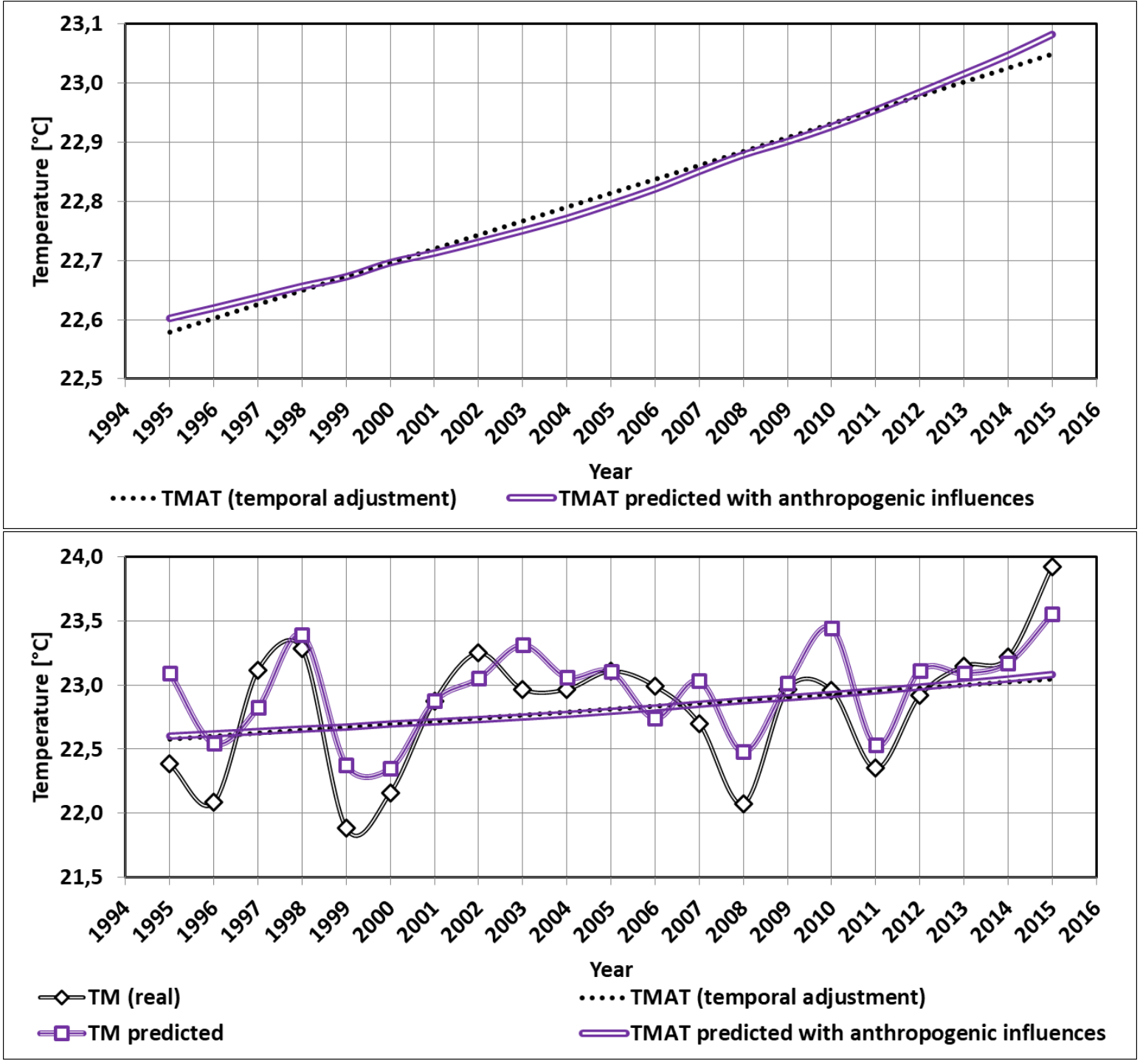

Figure 15. Results of the linear model based on activities influence factors. 
Table 10 presents the influence factors found for each of the variables. These have been interpreted as percentage influences, which give a relative idea of the importance of activities on temperature changes. In general it is observed that the equivalent population has the largest influence, followed by the extension of the urban area, the equivalent vehicles and the total energy. It is observed that in the developed model all the activities prove to be significant. Figure 15 shows the modeling of DTAM temperatures and TM temperatures as a result of modeling. To obtain modeled TM, the TBAT value, the DTSNM value and the result of modeling global and climatic changes for TM are added to modeled DTAM (see Equations 1 and 2)

Table 10. Influence factors found in the modeling.

\begin{tabular}{lll}
\hline Influential Activity $A i$ & Influence Factor $F A i$ & Influence \% \\
\hline Equivalent Men & 0,074 & $23,8 \%$ \\
Equivalent Vehicles & 0,050 & $16,0 \%$ \\
Total Energy & 0,050 & $16,0 \%$ \\
Food consumption & 0,016 & $5,3 \%$ \\
Urban Area & 0,059 & $18,9 \%$ \\
Urban Solid Waste & 0,030 & $9,8 \%$ \\
GDP & 0,032 & $10,1 \%$ \\
\hline
\end{tabular}

\subsection{Model based on Energy Balances}

Figure 16 shows the result of modeling DTAM and its comparison with the actual value of DTAM. It is observed that the resulting model is not linear.

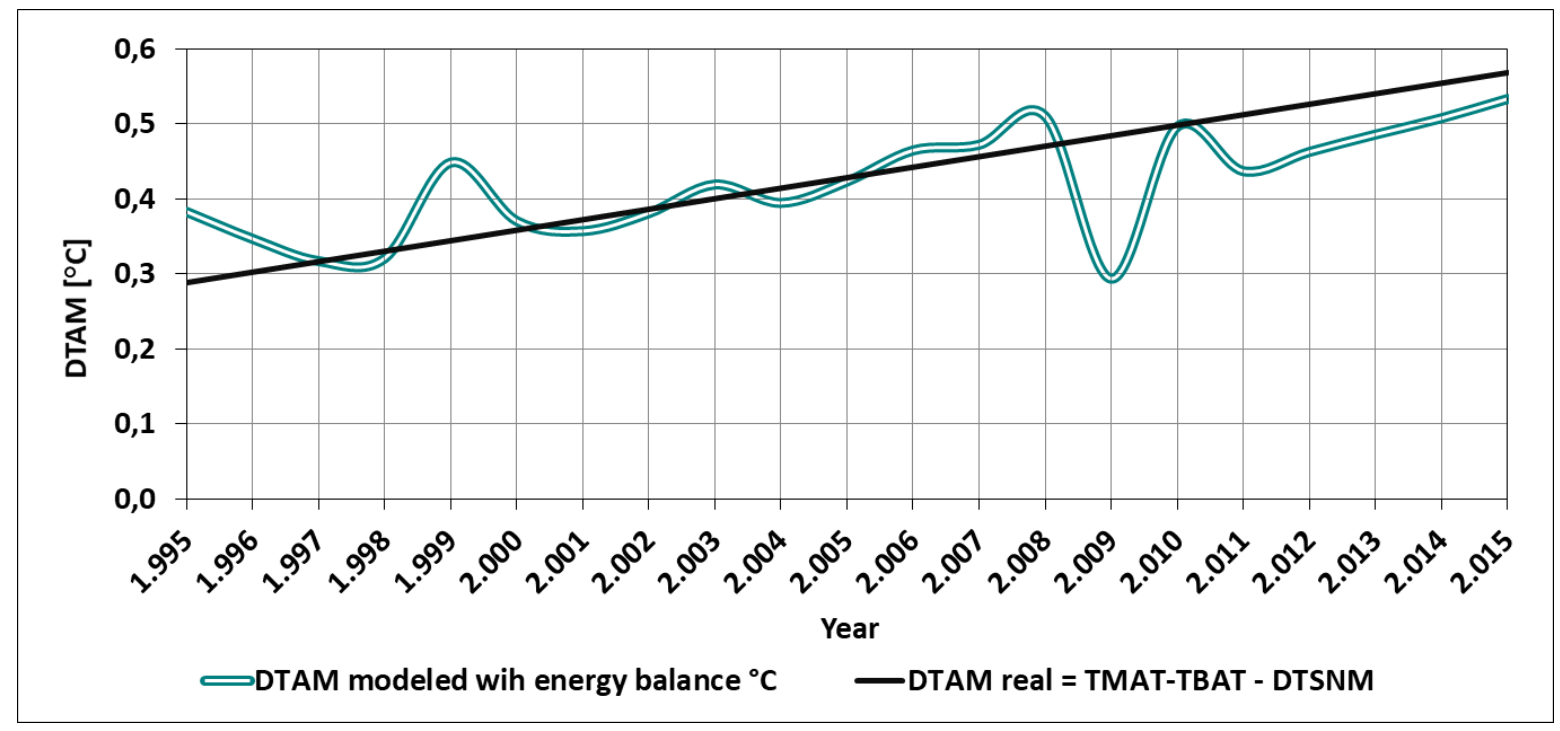

Figure 16. DTAM model results based on energy balances.

In the Figure 17 it is shown the combination of the results obtained in Sections $3.1+3.2$ and Sections $3.1+3.3$ for the temperature of Medellín (Olaya Herrera station)

\section{Conclusions}

Figure 18 shows, as a summary, how the temperature change accumulate over time in the studied period of 20 years, according to the interpretations presented in this study. 


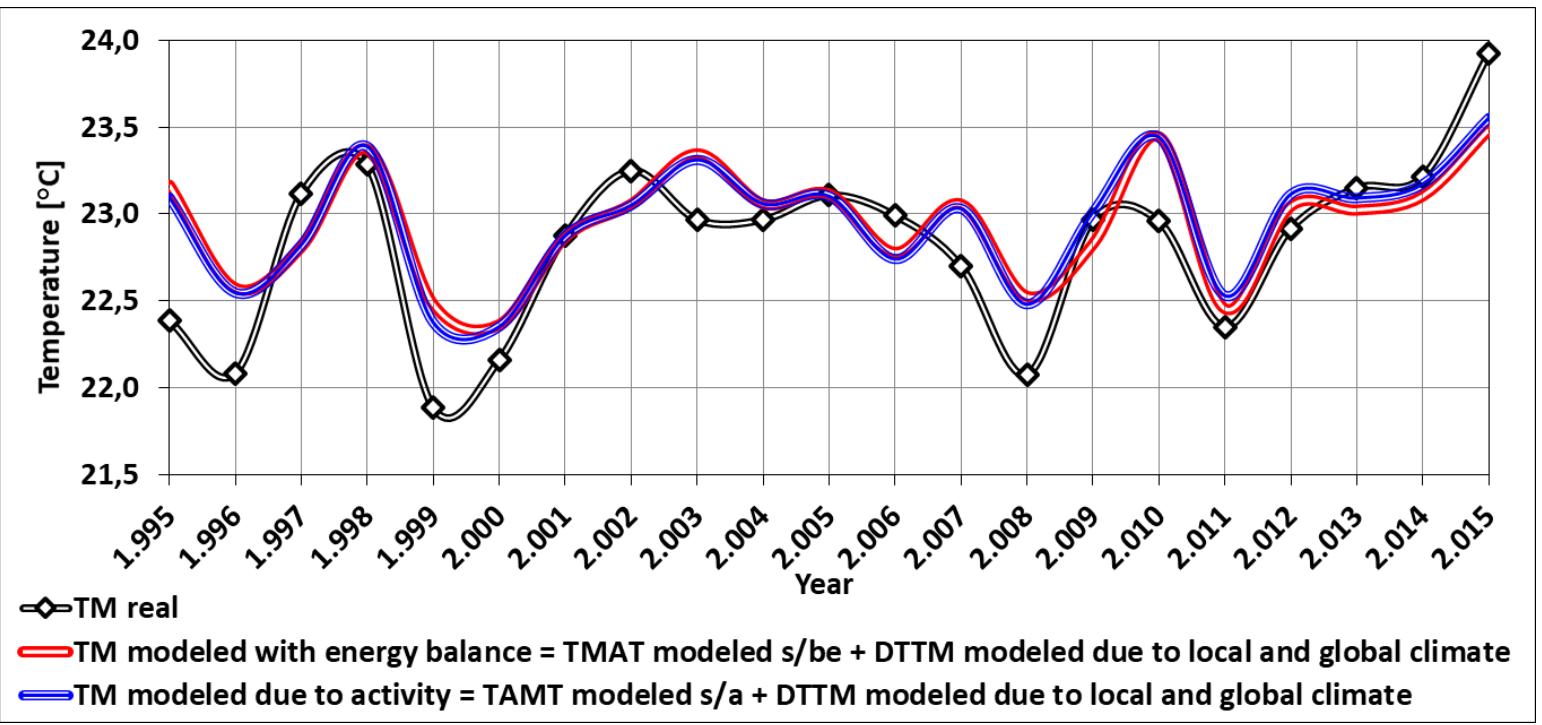

Figure 17. Results of the two models to predict TM and their comparison with the real temperatures.



Figure 18. Interpretation of changes and their trends over time.

In short, increases in mean temperature based on linear trends were found, they were estimated at $0.47^{\circ} \mathrm{C}$ in the 20 years studied from 1995 to 2015, of which $60 \%$ is as a result of local activity and $40 \%$ due to impact of global warming, as seen on Table 11; However, it is a complex behavior that shows increases and decreases and is not uniform in the three stations studied.

Table 11. Estimation of temperature change by type.

\begin{tabular}{lll}
\hline Type of change according to trends over time & Change, ${ }^{\mathbf{0}} \mathbf{C}$ & $\mathbf{\%}$ \\
\hline Changes from 1995 to 2015 according to linear trends & 0,47 & 100,0 \\
Changes from 1995 to 2015 attributable to global warming & 0,19 & 40,4 \\
Changes from 1995 to 2015 attributable to local human activity & 0,28 & 59,6 \\
\hline
\end{tabular}


In the results of the influence factors, it is observed that with the factors found and the values of the considered variables, a good approximation to the temperature adjustment due to the human activities is obtained. This represents a tool to estimate the temperature in the future considering the projections of the values of the variables.

Once it is taken into account which are the most influential factors, the influence of the daily activities of citizens on the increase of temperature can be analyzed. It is observed that the quantity of living beings is the most important influence and it is related to population growth, that in the case of the Metropolitan Area, it has been very influenced by the arrival of population from other parts of the department and the country, all due to best employment, health services and education opportunities in the area [27]. This situation can be mitigated or moderated by designing policies to improve the quality of life in rural areas, thus reducing the population exodus to the cities.

From the variables that have influence on the temperature, it is clear that everyone can act in some way to influence in a positive way on the human activities and on the elements that involve heating. For example, the use of facades and green ceilings can be promoted, with the presence of plant species or even painted in fresher colors that diminish the absorption of the incoming radiation; the heat emission can be reduced. In the case of plants, the radiation they absorb influences evapotranspiration processes, releasing water vapor which helps to cool the surrounding air [28]. Another consequence is that keeping the buildings cooler, the energy consumption of air conditioners and the release of heat related to them is reduced.

The results of the energy balance allow concluding that considering the environment of the metropolitan area as a control volume, despite the related simplifications, gives good results. This model seeks to calculate the temperature changes due human activity based on energy variables, which can be a useful tool for future predictions, as well as to identify the causes and propose local mitigation actions.

In both models it can be observed the influence of energy sources, fossil fuels and the consumption of electric energy, which make significant contributions. If energy consumption is reduced by means of energy saving actions and optimization, and a stimulation of mass transportation is promoted, a reduction of consumption of these sources will be real and thus the increment of the temperature will be reduced.

It is observed that in general the situation of temperature increments is due to the living habits of the population. If these become more sustainable, they will be effectively contributing to mitigating these increments.

\section{Recommendations}

In the realization of this study it was possible to better understand the state of the city and the importance of the monitoring various variables such as those proposed here, in order to understand climatic and environmental variations; not only can it lead to greater awareness and greater knowledge, but also to propose appropriate solutions to their reality.

The study also makes possible to see the importance of implementing a greater number of stations, measuring climate phenomena, especially temperatures, wind speeds and mixing heights, with the idea of having long-term data to see the progress in time and the consequences of the taken actions.

The authors propose the creation of an automated system to obtain the data and the creation of indicators, such as a warming index that will allow the public to know the actual increase in temperature due to urban or meteorological causes.

It was noted that there is an effective warm-up in the city that everyone feels, but it is also true that through initiatives such as saving energy and fuel, everyone can help to reduce it. In the metropolitan area there are avoidable and unavoidable energy consumptions, where for the first there is nothing more to rationalize the activity, and for the second, where the activity continues but technological updates are made to reduce the heat emissions, either by a post-process conditioning or decreasing energy consumption. 
Finally, it is recognized that living in a city has great advantages, such as the availability of resources and services, but at the same time the concentration of human activities brings problems that rural places do not have, which creates a certain contradiction between the enormous appeal of cities and the need to stimulate development in less populated areas, in pursuit of rationalizing and finding solutions to reduce the impact of human activity.

Acknowledgments: The authors would like to thank Hatch Indisa for allowing them to work on the research and publication of the article.

Author Contributions: Enrique Posada conceived and designed the model, Andrea Cadavid searched and processed the information, Enrique Posada and Andrea Cadavid performed the modeling, analyzed the data and wrote the paper. The authors would like to thank the Hatch Indisa intern David Robledo for helping with the gathering of information in the initial stages of the research.

Conflicts of Interest: The authors declare no conflict of interest.

\section{Abbreviations}

The following abbreviations are used in this manuscript:

AMVA: Metropolitan Area of the Valley of Aburrá

TM: Temperature of Medellín

TB: Temperature of Barbosa

TC: Temperature of Caldas

IDEAM: Colombian Institute of Hydrology, Meteorology and Environmental Studies

m.a.s.l.: meters above sea level

m.a.r.l.: meters above river level

CNG: Compressed natural gas

NOAA: American National Oceanic and Atmospheric Administration

DTGS95 annual: Temperature delta between the global annual temperature and the annual temperature for 1995 .

DTGS95 semi-annual: Temperature delta between the global semi-annual temperature and the annual temperature for 1995.

TB95: Average temperature of Barbosa in 1995.

TM95: Average temperature of Medellín in 1995.

TC95: Average temperature of Caldas in 1995.

TMAT: Temporal adjustment of the temperature of Medellín.

DTTM: Delta of temperature between the real temperature and its time adjustment for Medellín.

FIDT global: Global Niño and Niña factor, global DTGS vs. global average DTGS.

FIR: Radiation factor.

FIP: Precipitation factor.

DTSNM: Temperature delta because of the height above the sea level.

TBAT: Temporal adjustment of the temperature of Barbosa.

DTAM: Temperature delta due to anthropogenic activity of Medellín.

1. Loaiza Bran, J.F. Antioquia, entre dos o tres grados más caliente. Available online: http://www. elcolombiano.com/antioquia/antioquia-supera-temperatura-historica-dx3572630, accessed on 18 July 2016.

2. Gómez, R.V. Cómo Enfriar El Centro De Medellín. Available online: http:/ /www.elcolombiano.com/ antioquia/centro-de-medellin-afectado-por-altas-temperaturas-LD3342926, accessed on 18 July 2016.

3. Thompson, A. August ties with July as hottest month on record. Available online: https://www. theguardian.com/environment/2016/sep/13/august-ties-with-july-as-hottest-month-on-record, accessed on 19 September 2016. 
4. Xu, C.; Zhao, J.; Li, J.; Gao, S.; Zhou, R.; Liu, H.; Chen, Y. Climate change in Urumqi City during 1960-2013. Quaternary International 2015, 358, 93-100.

5. Huang, Q.; Lu, Y. The Effect of Urban Heat Island on Climate Warming in the Yangtze River Delta Urban Agglomeration in China. International journal of environmental research and public health 2015, 12, 8773-8789.

6. Fujibe, F. Detection of urban warming in recent temperature trends in Japan. International Journal of Climatology 2009, 29, 1811-1822.

7. Grimmond, S. Urbanization and global environmental change: local effects of urban warming. The Geographical Journal 2007, 173, 83-88.

8. Lauwaet, D.; De Ridder, K.; Saeed, S.; Brisson, E.; Chatterjee, F.; van Lipzig, N.; Maiheu, B.; Hooyberghs, H. Assessing the current and future urban heat island of Brussels. Urban Climate 2016, 15, 1-15.

9. Fuentes Pérez, C.A. Islas de calor urbano en Tampico, México: Impacto del microclima a la calidad del hábitat. Nova scientia 2015, 7, 495-515.

10. Stone, B. Urban and rural temperature trends in proximity to large US cities: 1951-2000. International Journal of Climatology 2007, 27, 1801-1807.

11. Djedjig, R.; Bozonnet, E.; Belarbi, R. Experimental study of the urban microclimate mitigation potential of green roofs and green walls in street canyons. International Journal of Low-Carbon Technologies 2015, 10, 34-44.

12. Malys, L.; Musy, M.; Inard, C. A hydrothermal model to assess the impact of green walls on urban microclimate and building energy consumption. Building and Environment 2014, 73, 187-197.

13. Sharma, S.; Pandey, D.; Agrawal, M.; Leal-Filho, W.; Paradowska, M. Global warming potential and sustainable management of three land uses in Varanasi. Management of Environmental Quality: An International Journal 2016, 27.

14. Kiss, V.M. Modelling the energy system of Pécs-The first step towards a sustainable city. Energy 2015, 80, 373-387.

15. Chow, W.T.; Salamanca, F.; Georgescu, M.; Mahalov, A.; Milne, J.M.; Ruddell, B.L. A multi-method and multi-scale approach for estimating city-wide anthropogenic heat fluxes. Atmospheric Environment 2014, $99,64-76$.

16. Song, T.; Yang, Z.; Chahine, T. Efficiency evaluation of material and energy flows, a case study of Chinese cities. Journal of Cleaner Production 2016, 112, 3667-3675.

17. Johansson, T.; Vesterlund, M.; Olofsson, T.; Dahl, J. Energy performance certificates and 3-dimensional city models as a means to reach national targets-A case study of the city of Kiruna. Energy Conversion and Management 2016, 116, 42-57.

18. Gómez Ceballos, D.J.; Morán Perafán, R. Análisis energético urbano usando metodologías de gestión integral de energía. Energética, pp. 23-31.

19. Díaz Álvarez, C.J. Metabolismo energético y calidad del aire en Bogotá DC: señal de insostenibilidad. Épsilon 2014, pp. 119-144.

20. Díaz Álvarez, C.J. Metabolismo de la ciudad de Bogotá DC: una herramienta para el análisis de la sostenibilidad ambiental urbana/Urban metabolism of the city of Bogota dc: a tool for environmental urban sustainability analysis. Thesis.

21. Díaz Álvarez, C.J. Metabolismo urbano: herramienta para la sustentabilidad de las ciudades. Interdisciplina 2014, 2.

22. IDEAM. ACERCA DE LA ENTIDAD. Available online: http://www.ideam.gov.co/web/entidad/acercaentidad, accessed on 18 July 2016.

23. Posada, E.; Mojica, D.; Pino, N.; Bustamante, C.; Pineda, A.M. ESTABLECIMIENTO DE ÍNDICES DE CALIDAD AMBIENTAL DE RÍOS CON BASES EN EL COMPORTAMIENTO DEL OXÍGENO DISUELTO Y DE LA TEMPERATURA. APLICACIÓN AL CASO DEL RÍO MEDELLÍN, EN EL VALLE DE ABURRÁ EN COLOMBIA ESTABLISHMENT OF ENVIRONMENTAL QUALITY INDICES. Dyna 2013, 181, 193.

24. Estrada, M.; Camacho, P.; Jesús, A.; Restrepo, C.; María, T.; Parra, M.; Carlos, M. Parámetros antropométricos de la población laboral colombiana 1995 (acopla95). Rev. Fac. Nac. Salud Pública 1998, 15, 112-139. 
550 26. Kennedy, C. Why did Earth's surface temperature stop rising in the past decade? Available 551 online: https://www.climate.gov/news-features/climate-qa/why-did-earth $\%$ E2 $\% 80 \% 99$ s-surface552 temperature-stop-rising-past-decade\#.WhR66tUpca0.link, accessed on 30 September 2016.

553 27. SILVA ARIAS, A.C.; GONZÁLEZ ROMÁN, P. UN ANÁLISIS ESPACIAL DE LAS MIGRACIONES 554 INTERNAS EN COLOMBIA (2000-2005). Revista Facultad de Ciencias Económicas: Investigación y Reflexión $555 \quad 2009,17,123-144$.

556 28. (UHIs), U.H.I. Home - The Urban Heat Island (UHI) Effect. Available online: http://www. urbanheatislands.com/home, accessed on 09 September 2015. 